\title{
Effective elimination of liver cancer stem-like cells by CD90 antibody targeted thermosensitive magnetoliposomes
}

\author{
Rui Yang ${ }^{1}$, Li Y. An ${ }^{2}$, Qin F. Miao ${ }^{1}$, Feng M. Li ${ }^{1}$, Yong Han ${ }^{1}$, Hui X. Wang ${ }^{1}$, Dang P. \\ Liu $^{1}$, Rong Chen ${ }^{3}$ and Sha Q. Tang ${ }^{1}$ \\ ${ }^{1}$ School of Medicine, Southeast University, Nanjing, People's Republic of China \\ 2 Jiangsu Key Laboratory of Molecular and Fuctional Imaging, Department of Radiology, Zhongda Hospital, Nanjing, People's \\ Republic of China \\ ${ }^{3}$ Department of Oncology, Zhongda Hospital, Nanjing, People's Republic of China \\ Correspondence to: Sha Q. Tang, email: panyixi-tas@163.com \\ Keywords: LCSCs; CD90; TMs; targeting therapy; hyperthermia therapy \\ Received: December 02,2015 Accepted: April 16, $2016 \quad$ Published: April 29, 2016
}

\section{ABSTRACT}

Aim: To investigate the use of thermosensitive magnetoliposomes (TMs) loaded with magnetic iron oxide $\left(\mathrm{Fe}_{3} \mathrm{O}_{4}\right)$ and the anti-cancer stem cell marker CD90 (CD90@ TMs) to target and kill CD90+ liver cancer stem cells (LCSCs).

Methods: The hepatocellular carcinoma cell line Huh7 was used to separate CD90+ LCSCs by magnetic-activated cell sorting. CD90@TMs was characterized and their ability to target CD90+ LCSCs was determined. Experiments were used to investigate whether CD90@TMs combined with magnetic hyperthermia could effectively eliminate CD90+ LCSCs.

Results: The present study demonstrated that CD90+ LCSCs with stem cells properties were successfully isolated. We also successfully prepared CD90@TMs that was almost spherical and uniform with an average diameter of $130 \pm 4.6 \mathrm{~nm}$ and determined that magnetic iron oxide could be incorporated and retained a superparamagnetic response. CD90@TMs showed good targeting and increased inhibition of CD90+ LCSCs in vitro and in vivo compared to TMs.

Conclusion: CD90@TMs can be used for controlled and targeted delivery of anticancer drugs, which may offer a promising alternative for HCC therapy.

\section{INTRODUCTION}

Hepatocellular carcinoma (HCC) is the third-leading cause of death worldwide [1], despite advances in cancer therapeutics. Liver cancer stem-like cells have been recognized in multiple subtypes of HCC and identified as a contributor to $\mathrm{HCC}$ initiation, relapse and metastasis [2]. CD90 is an important marker for liver cancer stemlike cells [3] found in all HCC cells and $91.6 \%$ of blood specimens from liver cancer patients [4]. A recent study on the relationship between liver cancer stem cells (LCSCs) and early recurrence of HCC indicated that early recurrence was related to expression of CD90 [5]. These studies suggest that $\mathrm{CD} 90^{+}$cells are important for HCC initiation, relapse and treatment. Moreover, $\mathrm{CD} 90^{+} \mathrm{HCC}$ cells, but not CD90- $\mathrm{HCC}$ cells, caused tumor formation in immunodeficient mice. In addition, when gene expression was compared in $\mathrm{CD} 90^{+}$LCSCs and pericarcinomatous tissue, $\mathrm{CD} 90^{+} \mathrm{HCC}$ cells expressed genes that contributed to inflammation and drug resistance [6], suggesting that CD90 was a more sensitive and specific marker of liver cancer stem-like cells in HCC. So in our previous study, $\mathrm{CD} 90^{+}$liver cancer stem-like cells were referred to as $\mathrm{CD} 0^{+}$LCSCs. However, few treatments specifically target LCSCs, which may contribute to the poor prognosis of HCC patients. Thus, synthesizing a compound that can selectively scavenge CD90 ${ }^{+}$LCSCs for treatment of HCC cells would generate much interest.

Radiotherapy and chemotherapy have long been the conventional tumor treatment modalities. However, resistance reduces efficacy and often gives rise to recurrence. Recent studies demonstrated that increased 
expression of breast cancer resistance protein 1 (BCRP1) [7] and $\mathrm{O}$ (6)-methylguanine-DNA methyltransferase (MGMT) [8] were responsible for chemoresistance by cancer stem cells (CSCs). Another study showed that repair mechanisms in response to DNA damage by radiation caused radioresistance [9]. Therefore, developing novel approaches to eradicate CSCs shows promise for radical elimination of tumors.

Recent studies have focused on eradicating CSCs by magnetic hyperthermia because of its important roles in improving sensitivity to chemotherapy [10] and radiotherapy [11], as well as in overcoming drug resistance [12]. Sadhukha et al. [13] stated that CSCs could be eliminated by magnetic hyperthermia, while in fact CSCs exhibited increased tolerance than non-CSCs to radiotherapy and chemotherapy. This supports the investigation of magnetic hyperthermia as a new and more effective treatment for CSCs compared with radiotherapy and chemotherapy.

Despite these advantages, conventional hyperthermia therapy failed to alleviate toxicity due to dispersed heating of the adjacent organs and normal tissue [14]. To solve this problem, magnetic hyperthermia, which was initially proposed by Gilchrist, has been promoted as a tumor heat treatment that can precisely deliver heat to the site of action [15]. The temperature of the tissue can be controlled by an external magnetic field; therefore, no thermal damage to non-target zones occurs. Superparamagnetic $\mathrm{Fe}_{3} \mathrm{O}_{4}$ nanoparticles have considerable magnetism, catalysis, and wave absorption properties, making them the most commonly used magnetic fluid for tumor hyperthermia [16]. $\mathrm{Fe}_{3} \mathrm{O}_{4}$ loaded with drugs can enhance drug concentration in the target with the assistance of an external magnetic field to improve therapeutic tumor efficacy while reducing normal tissue toxicity. In addition, $\mathrm{Fe}_{3} \mathrm{O}_{4}$ can be used as a contrast agent in magnetic resonance imaging (MRI) to follow drug distribution. When placed in alternating magnetic field (AMF), it generates thermal energy that can be used to induce hyperthermia and control the release of drugs [17, 18]. However, a short half-life, lack of active targeting ability and removal by macrophages in the mononuclear phagocytic system (MPS) has limited its application [19]. To overcome these problems, liposomes have been loaded with $\mathrm{Fe}_{3} \mathrm{O}_{4}$ and polyethylene glycol (PEG) to facilitate membrane insertion. In this study, the thermalsensitive lipid, dipalmitoylphosphatidylcholine (DPPC), was selected as a membrane material to enhance the controllability of $\mathrm{Fe}_{3} \mathrm{O}_{4}$ and efficacy against hyperthermia (Scheme 1). Thermal-sensitive lipsomes is an ideal

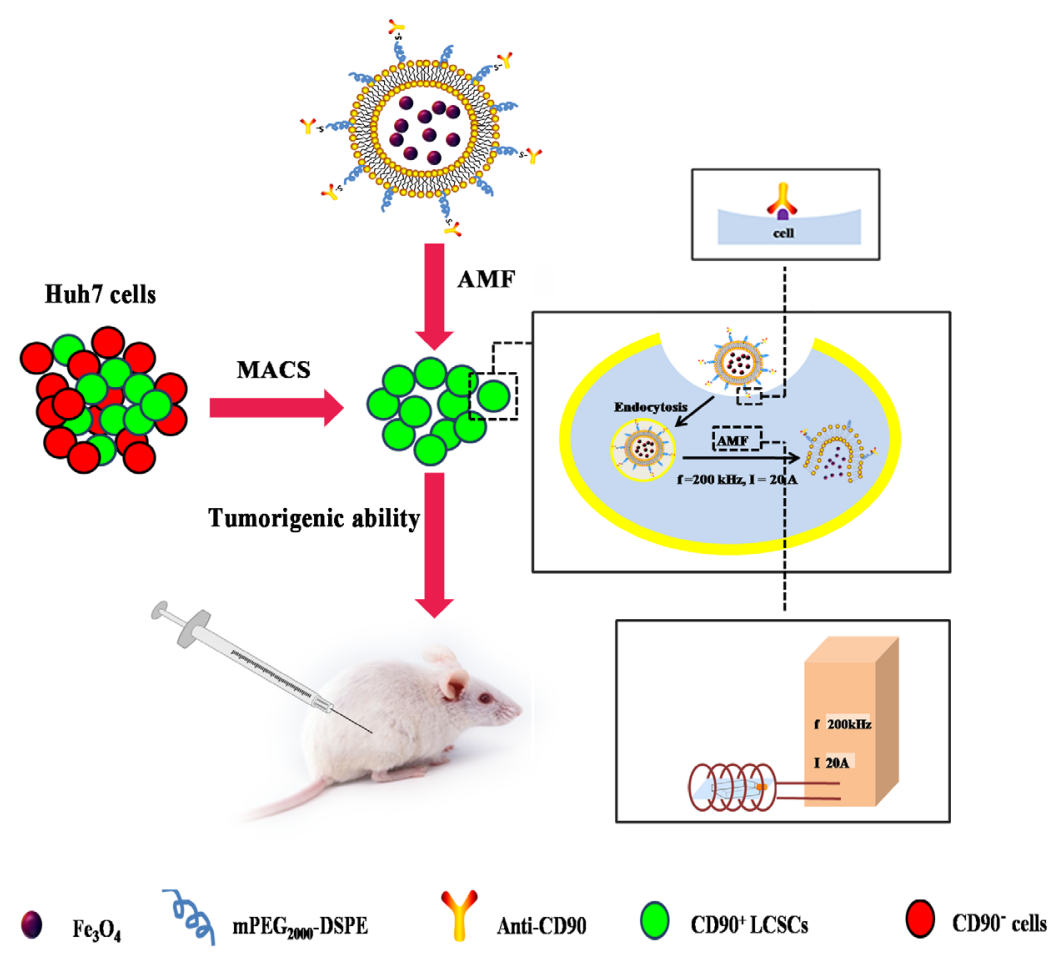

Scheme 1: Effective elimination of LCSCs by CD90@TMs. The TMs and CD90@TMs was prepared to target and kill CD90+ LCSCs. It was demonstrated that CD90+ LCSCs could be effectively ablated by CD90@TMs. Magnetic hyperthermia-treated CD90 LCSCs could cause a significant delay in tumor initiation in vivo tumor initiation study. CD90@TMs showed higher inhibition rate of tumor mass and tumor volume compared to TMs in hepatocarcinoma-bearing mice. Abbreviations: CD90, cluster of differentiation 90; PEG $_{2000}$-DSPE, 1,2-distearoyl-sn-glycero-3-phosphoethanolamine-N-[methoxy(polyethylene glycol) -2000]; TMs, thermosensitive magnetoliposomes; LCSCs, live cancer stem cells; AMF, alternating magnetic field; MACS, magnetic-activated cell sorting. 
approach for drugs when combined with hyperthermia. The release situation can be adjusted by the temperature. The drug release percents of the thermal-sensitive lipsomes are improved significantly when the temperature is higher than the phase transition temperature, while it releases less in non-heated organs [19].

To our knowledge, there are few reports describing the influence of magnetic hyperthermia for LCSCs and non-LCSCs. In this study, we successfully isolated CD90 LCSCs and determined their sensitivity to magnetic hyperthermia. CD90 thermosensitive magnetoliposomes (CD90@TMs) was subsequently prepared to target CD90 ${ }^{+} \mathrm{LCSCs}$ and we explored whether CD90 ${ }^{+} \mathrm{LCSCs}$ could be effectively ablated by CD90@TMs (Scheme 1). In vivo tumor initiation study performed in mice showed a significant delay in tumor initiation with CD90@TMs mediated magnetic hyperthermia-treated cells compared to the controls. The results demonstrate for the first time that CD90@TMs facilitates drug delivery to LCSCs, and CD90@TMs mediated hyperthermia efficiently induced death of CD90 $0^{+}$LCSCs.

\section{RESULTS AND DISCUSSION}

\section{Characterization of CD90@TMs}

Liposome is a commonly used drug vector that facilitates drug targeting and delays release, while reducing the dose and drug toxicity [19]. However, the
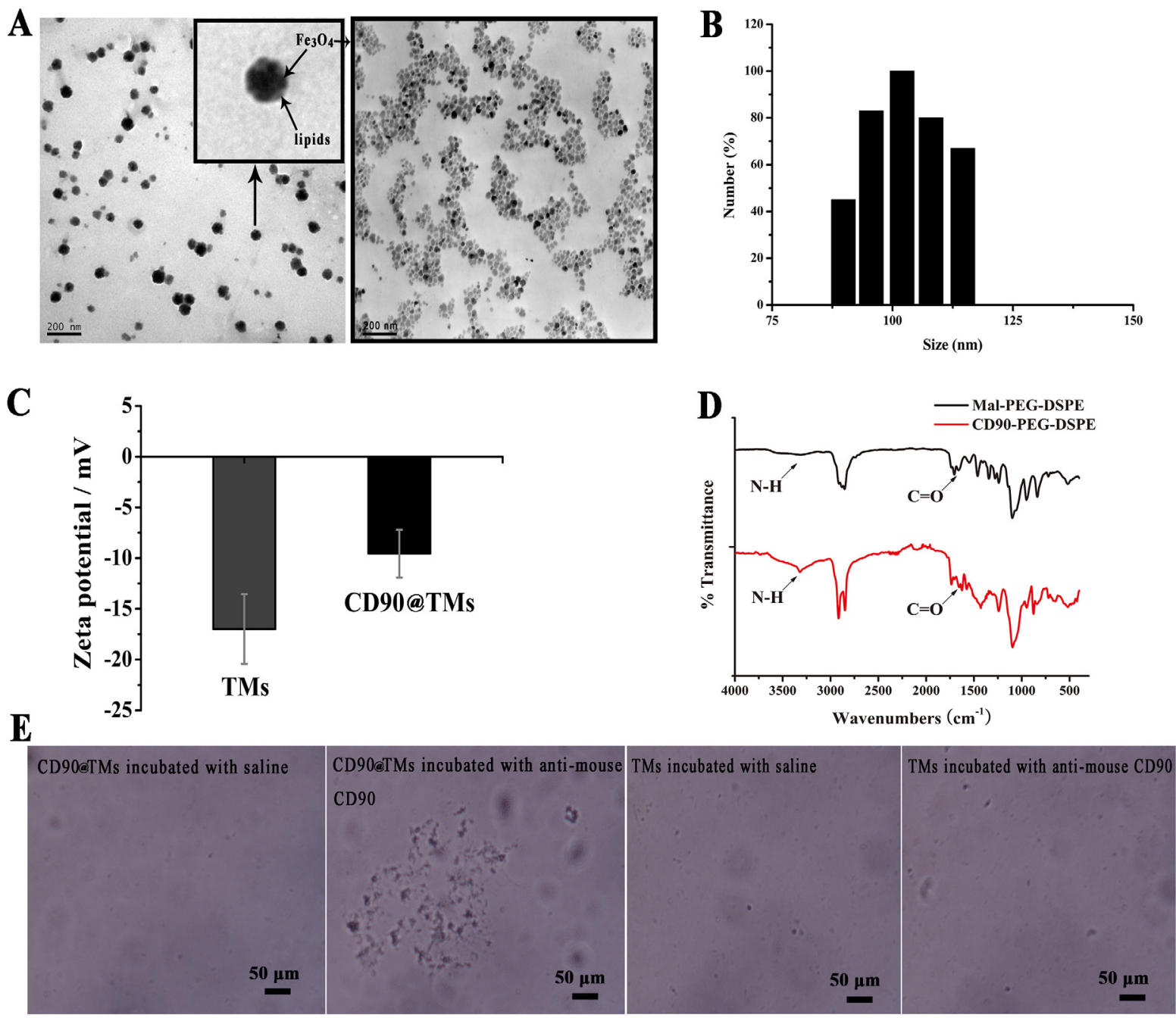

Figure 1: Characterization of CD90@TMs. A. TEM image of $\mathrm{Fe}_{3} \mathrm{O}_{4}$ and CD90@TMs $($ The bar = $200 \mathrm{~nm})$. B. Liposomes size determined by ZetaPlus. C. Zeta potentials determined by ZetaPlus (mean $\pm \mathrm{SD}, n=3$ ). D. FTIR spectra of $\mathrm{Mal}_{-} \mathrm{PEG}_{2000}-\mathrm{DSPE}$ and

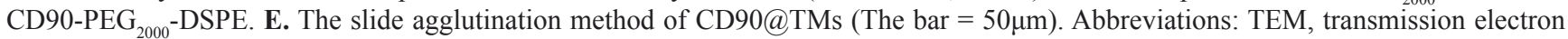
microscope; TMs, thermosensitive magnetoliposomes; FTIR, fourier translation infrared spectroscopy; PEG $_{2000}$-DSPE, 1,2-distearoyl-snglycero-3-phosphoethanolamine-N-[methoxy(polyethylene glycol)-2000]; CD90, cluster of differentiation 90. 
MPS can cause rapid elimination and is a major challenge in improving the therapeutic index of liposomes for tumors. In this study, TMs was coated with PEG to avoid the MPS and prolong circulation time [20] and an antiCD90 monoclonal antibody (MAb) was conjugated to TMs. The regression equation between the absorbance values and the concentration of anti-CD90 was $\mathrm{A}=18.89 \mathrm{C}-0.66$. $\mathrm{A}$ and $\mathrm{C}$ are the absorbance values and the concentration of anti-CD90, respectively. The regression equation of the phospholipids was $\mathrm{Y}=16.83 \mathrm{X}+0.22$. $\mathrm{Y}$ and $\mathrm{X}$ are the absorbance values and the concentration of phospholipids, respectively. The coupling efficiency of anti-human CD90 was $60.33 \% \pm 5.78$, corresponding to approximate 8 antibody molecules per liposome. $\mathrm{Fe}_{3} \mathrm{O}_{4}$ incorporated in the targeted TMs can be visualized by transmission electron microscope (TEM) (Figure 1A). $\mathrm{Fe}_{3} \mathrm{O}_{4}$ was clustered with a diameter of 10-20 nm. Lipids layer of CD90@TMs was visible in correlative TEM image [21]. The average particle size in water was $130 \pm 4.6$ $\mathrm{nm}$ (Figure 1B) and zeta potentials were negative (Figure 1C). The combination of anti-human CD90 to maleimide1,2-distearoyl-sn-glycero-3-phosphoethanolamine-N[methoxy(polyethylene glycol)-2000] (Mal-PEG ${ }_{2000}{ }^{-}$ DSPE) was detected by fourier transform infrared spectroscopy (FTIR) (Figure 1D). The spectrum of Mal$\mathrm{PEG}_{2000}$-DSPE showed weak $\mathrm{C}=\mathrm{O}$ peak between 3600 $\mathrm{cm}^{-1}$ and $3200 \mathrm{~cm}^{-1}$ and weak N-H in $1674 \mathrm{~cm}^{-1}$. However, both of the two peaks increased in the spectrum of CD90$\mathrm{PEG}_{2000}$-DSPE, indicating the successful combination of CD90 to Mal-PEG ${ }_{2000}-\mathrm{DSPE}$. In the slide agglutination assay, when anti-mouse CD90 was added to CD90@ TMs, an agglutination reaction formed, while saline added to CD90@TMs resulted in uniform scattering and no agglutination reaction was seen in control TMs (Figure 1E). The result further showed that the successful combination of anti-human CD90 to TMs.

When the temperature reaches the phase transition temperature, the lipid membrane of the thermosensitive liposomes is altered and the drugs in liposomes will leak out and diffuse into the target organ based on the concentration gradient. In contrast, unheated organs will have relatively low drug concentrations, which will reduce side effects. Based on this, in this study we used magnetic hyperthermia and thermosensitive liposomes to improve therapeutic effectiveness by accumulating drugs in the tumors. The phase transition temperature of CD90@TMs was evaluated by differential scanning calorimeter (DSC) (Figure 2A) and showed little change compared with pure DPPC $\left(41.9\right.$ vs. $\left.42^{\circ} \mathrm{C}\right)$. Temperaturesensitive release property in vitro was detected by the dynamic dialysis method at $37 \pm 0.5^{\circ} \mathrm{C}$ and $41.9 \pm$ $0.5^{\circ} \mathrm{C}$. To evaluate the cumulative release rate, lissamine rhodamine $\mathrm{B}(\mathrm{Rh})$ was wrapped into the aqueous phase of the CD90@TMs to form CD90-Rh/TMs. The cumulative release rate of free $\mathrm{Rh}$ was five to seven-fold higher than $\mathrm{CD} 90-\mathrm{Rh} / \mathrm{TMs}$ at $37 \pm 0.5^{\circ} \mathrm{C}$ after $1 \mathrm{~h}$ (Figure $2 \mathrm{~B}$ ). However, the cumulative CD90-Rh/TMs release rate was $<30 \%$ after $120 \mathrm{~h}$, which suggested that CD90-Rh/TMs was more stable at temperatures $<$ the phase transition temperature. Meanwhile, the CD90-Rh/TMs showed a different release profile at a temperature near the phase transition temperature (Figure $2 \mathrm{C}$ ). The cumulative release rate reached $50 \%$ after $24 \mathrm{~h}$ and $81 \%$ after $120 \mathrm{~h}$. Thus, the as-synthesized DPPC-based liposomes showed good temperature-sensitive release property.

Specific absorption rate (SAR) is an important magnetic field parameter that induces heating and determines the magnetocaloric effect to the tumor in the presence of an AMF [22]. The SAR value of the CD90@ TMs was $84 \pm 1.1 \mathrm{w} / \mathrm{g}$. It was higher than pure $\mathrm{Fe}_{3} \mathrm{O}_{4}$ $(67.2 \pm 1.2 \mathrm{w} / \mathrm{g})$. This result was consistent with a previous report [23]. In addition, the iron content was $1.9 \mathrm{mg} / \mathrm{mL}$. All of the hysteresis loops of the pure $\mathrm{Fe}_{3} \mathrm{O}_{4}$ and CD90@ TMs shown in Figure 2D were superparamagnetic, which indicated that liposomes wrapped with $\mathrm{Fe}_{3} \mathrm{O}_{4}$ retained a superparamagnetic response. The results of thermodynamic test using different iron concentrations during AMF are shown in Figure 2E. The concentration of $\mathrm{Fe}_{3} \mathrm{O}_{4}$ inside the targeted liposomes was positively related to the temperature when the AMF intensity was fixed. During the initial $0.5 \mathrm{~h}$, the sample showed a rapid temperature increase, which slowed after 25-30min. After $30 \mathrm{~min}$, the temperature remained constant. $0.34 \mathrm{mg} / \mathrm{mL}$ Fe reached a temperature of $44^{\circ} \mathrm{C}$ and remained stable, which is within the effective treatment temperature range of $41-46^{\circ} \mathrm{C}$.

To assess the stability of the targeted liposomes, the hydrodynamic size and encapsulation efficiency of CD90$\mathrm{Rh} / \mathrm{TMs}$ was determined in phosphate buffered saline (PBS, Figure 2F) or dulbecco's modified eagle media: nutrient mixture F-12 (DMEM/F-12, Figure 2G) medium. The stability of liposomes is an important consideration before a new efficient drug-loaded nano-system can be established and the change in mean particle size and encapsulation efficiency over time is a useful indicator of the stability of liposomal suspensions [24]. The hydrodynamic size of CD90-Rh/TMs and encapsulation efficiency of $\mathrm{Rh}$ showed no noticeable change over 4 weeks in two different solutions (Figure $2 \mathrm{~F}$ and $2 \mathrm{G}$ ), which indicated that the liposomes were stable and retained the encapsulated $\mathrm{Rh}$ when stored at $4^{\circ} \mathrm{C}$.

\section{Analysis of cellular proliferation, differentiation, colony formation, migration and invasion and $i n$ vivo tumor formation}

CD90 can be used as a marker for a variety of stem cells, in addition to LCSCs and plays a role in the development of HCC $[3,4]$. LCSCs can be enriched 
Table 1: The fluorescence intensity of sorted positive, sorted negative and unsorted cells cultured with CD90 conjunct $\mathrm{Rh} / \mathrm{TMs}$ and non-specific antibody conjunct $\mathrm{Rh} / \mathrm{TMs}$ detected by confocal microscopy

\begin{tabular}{|l|l|l|l|}
\hline & Huh7 & CD90 $^{-}$Huh7 & CD90 $^{+}$LCSCs \\
\hline & $(\overline{\mathbf{x}} \pm \mathbf{S}, \boldsymbol{n}=\mathbf{3})$ & $(\overline{\mathbf{x}} \pm \mathbf{S}, \boldsymbol{n}=\mathbf{3})$ & $(\overline{\mathbf{x}} \pm \mathbf{S}, \boldsymbol{n}=\mathbf{3})$ \\
\hline Control & $326.1 \pm 27.2$ & $342.4 \pm 31.5$ & $360.1 \pm 34.1$ \\
\hline CD20@TMs & $332.4 \pm 26.5$ & $337.5 \pm 53.6$ & $315.6 \pm 30.3$ \\
\hline CD90@TMs & $664.7 \pm 34.1$ & $324.5 \pm 33.2$ & $3589.5 \pm 47.2^{* *}$ \\
\hline
\end{tabular}

Notes: Data are presented as means \pm standard deviation. Edach experiment was repeated at least three times. **Comparisons with the control group of CD90 $0^{+} \mathrm{LCSC}, P<0.05$.

Table 2: $T_{2}$ relaxation time(ms) of sorted positive, sorted negative and unsorted cells cultured with CD90 conjunct TMs and non-specific antibody conjunct TMs

\begin{tabular}{|l|l|l|l|}
\hline & Huh7 & CD90 $^{-}$Huh7 & CD90 $^{+}$LCSCs \\
\hline & $(\overline{\mathbf{x}} \pm \mathbf{S}, \boldsymbol{n}=\mathbf{3})$ & $(\overline{\mathbf{x}} \pm \mathbf{S}, \boldsymbol{n}=\mathbf{3})$ & $(\overline{\mathbf{x}} \pm \mathbf{S}, \boldsymbol{n}=\mathbf{3})$ \\
\hline Control & $66.4 \pm 5.8$ & $59.6 \pm 4.7$ & $60.4 \pm 4.9$ \\
\hline CD20@TMs & $61.3 \pm 3.9$ & $68.3 \pm 3.6$ & $62.4 \pm 6.6$ \\
\hline CD90@TMs & $40.6 \pm 4.9$ & $59.5 \pm 6.8$ & $18.9 \pm 5.6^{* *}$ \\
\hline
\end{tabular}

Notes: Data are presented as means \pm standard deviation. Each experiment was repeated at least three times. ${ }^{*}$ Comparisons with the control group of CD90 LCSCs, $P<0.05$.

through fluorescence-activated cell sorting (FACS) and magnetic-activated cell sorting (MACS) using various cell surface markers. In this study, CD90 ${ }^{+}$LCSCs were isolated by MACS. The baseline expression of CD90 in whole populations of Huh7 cells in vitro was approximately $6.9 \pm 1.8 \%$ (Figure $3 \mathrm{~A}$ ). The purity of the sorted $\mathrm{CD} 90^{+}$ cells and sorted CD90 cells after magnetic separation was $90.8 \pm 4.9 \%$ and $0.7 \pm 0.6 \%$, respectively(Figure $3 \mathrm{~A}$ ). The viability of the sorted $\mathrm{CD} 90^{+}$cells and sorted CD90 cells after magnetic separation was about $99.1 \pm 1.9 \%$ and $98.9 \pm 1.2 \%$. Spheroids formed during maintenance in DMEM/F12 medium for 7 days (Figure 3B). Cell proliferation assays indicated that the growth rate of CD $90^{+}$LCSCs was significantly higher compared to that of $\mathrm{CD} 90^{-} \mathrm{Huh} 7$ cells up to 7 days after cell sorting $\left(P<0.05\right.$, Figure 3C). It means that $\mathrm{CD} 90^{+} \mathrm{LCSCs}$ have a capacity for self-renewal. Flow cytometry was used to analyze the change of expression of CD90 in CD90 $0^{+}$ LCSCs cultured with DMEM containing 10\% FBS for 1 week. As shown in Figure 3D, the percentage of $\mathrm{CD}^{+} 0^{+}$ cells dramatically decreased with culture time. After 1 week, the percentage of $\mathrm{CD} 90^{+}$cells had dropped to $6.2 \%$, which was similar to the percentage in non-sorted Huh7 cells. The increase of OD value in $\mathrm{CD} 90^{+} \mathrm{LCSC}$ group was due not to the fast proliferation of $\mathrm{CD} 90^{+}$cells but to an increase in the number of CD90- cells. These results demonstrate that $\mathrm{CD} 90^{+}$LCSCs, which are a small and rare subset of Huh 7 cells, have a capacity for self-renewal and differentiation to produce descendent CD90- cells in culture. To determine the drug resistance of $\mathrm{CD} 90^{+}$ LCSCs, the cells were treated with doxorubicin (DOX) at different concentrations, and the half maximal inhibitory concentration (IC50) values were calculated. Compared to CD90- Huh7 cells, CD90+ LCSCs were more resistant to
DOX (Figure 3E). The IC50 of CD $90^{+}$LCSCs and CD90Huh7 cells were $12.6 \pm 1.04 \mu \mathrm{g} / \mathrm{mL}$ and $1.07 \pm 0.13 \mu \mathrm{g} / \mathrm{mL}$, respectively. Furthermore, CD90 $0^{+} \mathrm{LCSCs}$ exhibited higher ability of colony formation and invasion than CD90 Huh7 cells $\left(P<0.05\right.$, Figure 3F, 3G). CD90 $0^{+}$cells sorted from liver cancer cell lines, liver cancer tissues or the peripheral blood of HCC patients displayed tumorigenic and metastatic capacity when injected into immunodeficient mice $[3,4,25]$. To determine whether the CD $90^{+}$LCSCs possessed a stem cell phenotype in vivo, xenograft tumors were induced by the subcutaneous injection of 2 $\times 10^{4}$ cells. The mice injected with CD90 ${ }^{+} \mathrm{LCSCs}$ formed tumors while CD90- Huh7 cells formed no tumors after 3 weeks of observation. Two month after inoculation, all mice injected with $\mathrm{CD} 90^{+} \mathrm{LCSC}$ s developed tumors, whereas mouse inoculated with $\mathrm{CD} 90^{-} \mathrm{Huh} 7$ developed no tumors. The incidence of tumor xenografts in the $\mathrm{CD} 90^{+}$ group was significantly higher than that in the CD90group (100\% vs. $5.7 \pm 9.8 \%)$. Hematoxylin-eosin (HE) staining showed that tumor xenografts from implanted $\mathrm{CD} 0^{+}$LCSCs had histological features similar to Huh7 cells (Figure $3 \mathrm{H}$ ). Immunohistochemical (IHC) staining showed that the expression rates of the $\mathrm{CD} 90^{+}$LCSCs transplantation group and the parent Huh7 established tumor group were $18.6 \pm 5.9 \%$ and $20.3 \pm 4.8 \%$, respectively. It meant that $\mathrm{CD} 90^{+} \mathrm{LCSCs}$ could also produced CD90cells in vivo. These results showed that the $\mathrm{CD} 90^{+} \mathrm{LCSCs}$ isolated from Huh7 cells possessed the characteristics of CSCs. 


\section{Targeting ability of $\mathrm{CD} 90-\mathrm{Rh} / \mathrm{TMs}$ for $\mathrm{CD}^{+}$ LCSCs in vitro}

To investigate whether the CD90-Rh/TMs could target $\mathrm{CD} 90^{+} \mathrm{LCSCs}$ in vitro, $\mathrm{Rh}$ encapsulated in those liposomes were incubated with cells and evaluated. Anti-CD19-targeted liposomes have been shown to be rapidly internalized into human B-lymphoma (Namalwa) cells within $60 \mathrm{~min}$ [26]. Using confocal microscopy, the fluorescence intensity of Rh (red) in CD90 targeted groups was higher than those of the control group and free $\mathrm{Rh}$ (Figure 4A, 4B), which was consistent with the flow cytometry results(Figure 4C). In flow cytometry results, uptake of $\mathrm{CD} 90-\mathrm{Rh} / \mathrm{TMs}$ by LCSCs was higher than that of $\mathrm{Rh} / \mathrm{TMs}$ and $\mathrm{CD} 90^{-}$cells but lower than $\mathrm{Rh}$ (Figure $4 \mathrm{C}$ ). The uptake of $\mathrm{CD} 90-\mathrm{Rh} / \mathrm{TMs}$ and $\mathrm{Rh} / \mathrm{TMs}$ was lower than free $\mathrm{Rh}$, which indicated that free Rh could cross the cell membrane and be efficiently enriched. However, these parameters were markedly different in vivo. Gabizon found that the removal rate of free doxorubicin was 450 -fold higher than that of PEG-modified liposomes [27]. Owing to the biocompatible PEG modified on the membrane, liposomes hold over opsonization and consequently lead to comparatively longer blood circulation times, thus creating possibilities to target cancers when coated on target agents. These two results suggested that the CD90$\mathrm{Rh} / \mathrm{TMs}$ could be used to effectively deliver drugs into the cell.
A

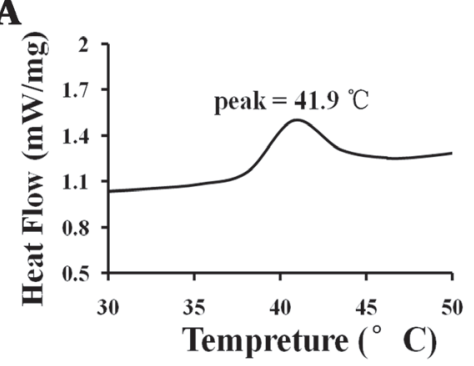

D

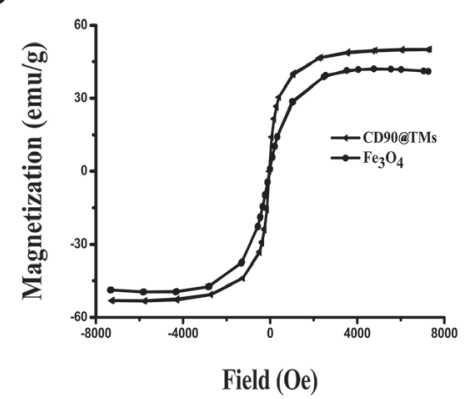

B

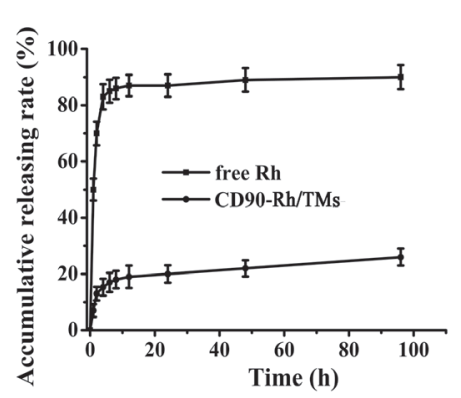

$\mathbf{E}$

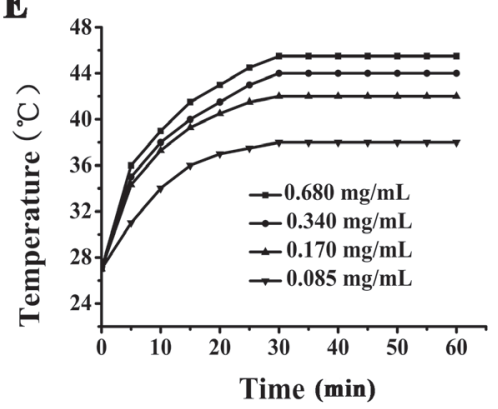

C

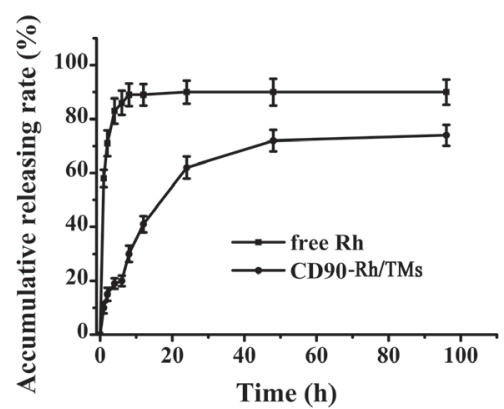

F

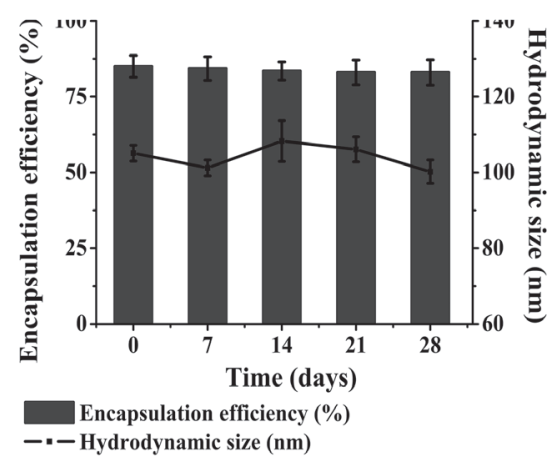

G

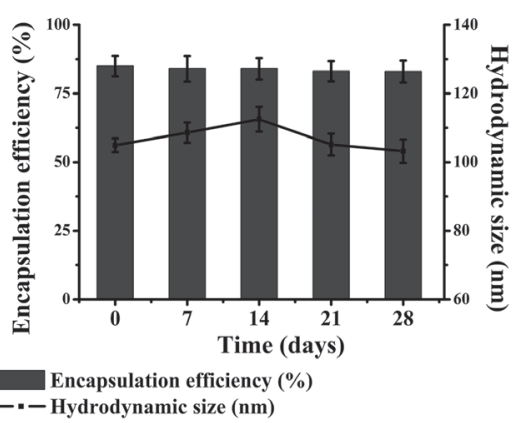

Figure 2: The characteristics of CD90@TMs. A. Phase transition temperature of the CD90@TMs. B. Drug release property of Rh from the $\mathrm{CD} 90-\mathrm{Rh} / \mathrm{TMs}$ and free $\mathrm{Rh}$ solution in vitro at $37 \pm 0.5^{\circ} \mathrm{C}$ (mean $\pm \mathrm{SD}, n=3$ ). $\mathrm{C}$. Release property of $\mathrm{Rh}$ from the $\mathrm{CD} 90-\mathrm{Rh} / \mathrm{TMs}$ and free Rh solution in vitro at $42 \pm 0.5{ }^{\circ} \mathrm{C}$ (mean $\pm \mathrm{SD}, n=3$ ). D. Hysteresis Loops of $\mathrm{Fe}_{3} \mathrm{O}_{4}$ and $\mathrm{CD} 90 @ \mathrm{TMs}$. E. Temperature increase curve of the CD90@TMs under an AMF ( $\mathrm{f}=200 \mathrm{kHz}, \mathrm{I}=20 \mathrm{~A}$ ). F. Physical stability of CD90-Rh/TMs in PBS at $4{ }^{\circ} \mathrm{C}$ by the end of 1 , 2, 3 and 4 weeks (mean $\pm \mathrm{SD}, n=3$ ). G. Physical stability of CD90-Rh/TMs in DMEM/F12 medium at $4{ }^{\circ} \mathrm{C}$ by the end of $1,2,3$ and 4 weeks (mean $\pm \mathrm{SD}, n=3$ ). Abbreviations: TMs, thermosensitive magnetoliposomes; CD90, cluster of differentiation 90; Rh, Lissamine rhodamine B; DSC, differential scanning calorimeter; AMF, alternating magnetic field; DMEM/F12, Dulbecco's Modified Eagle Media: Nutrient Mixture F-12. 

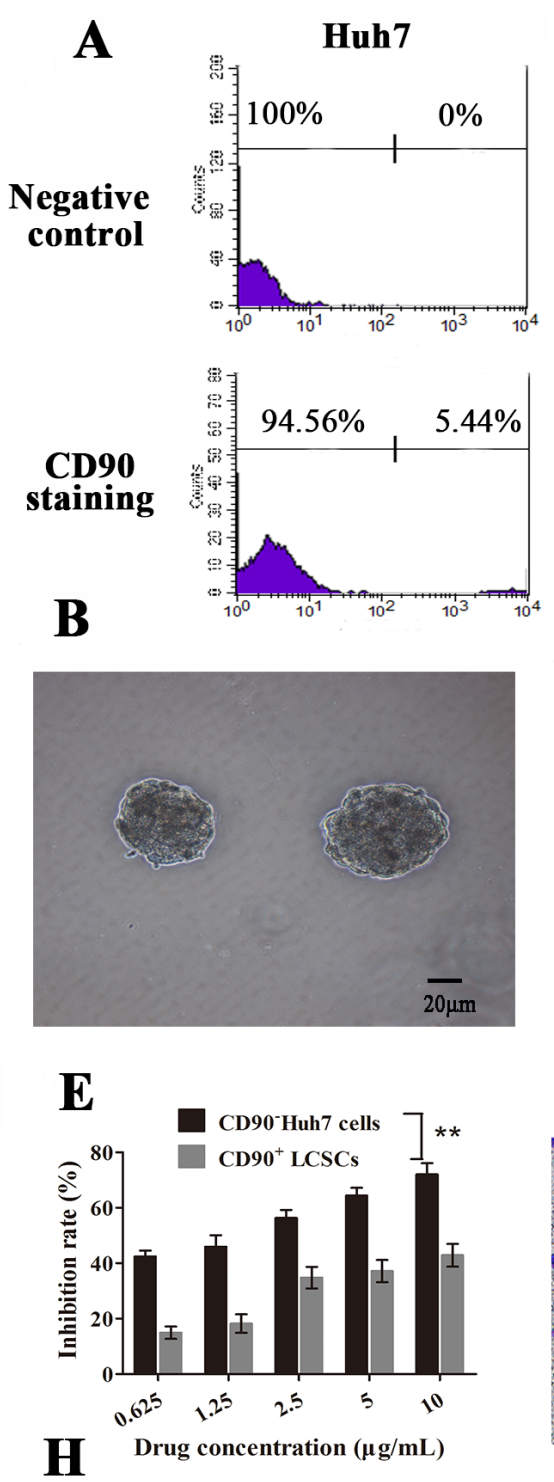

H Drug concentration $(\mu \mathrm{g} / \mathrm{mL})$
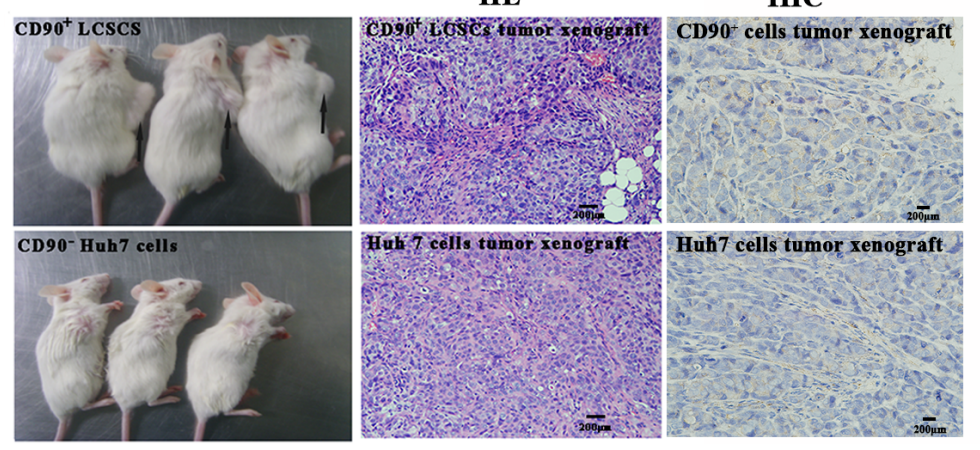

F ${ }_{\operatorname{CD} 90^{+} \mathrm{LCSCS}}$

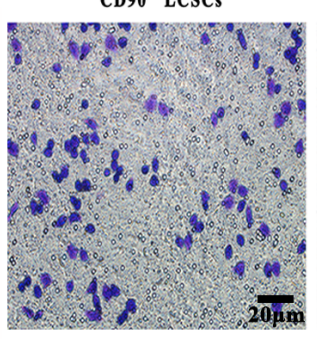

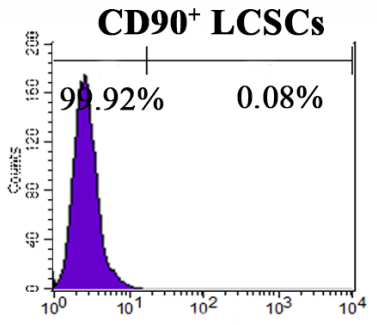
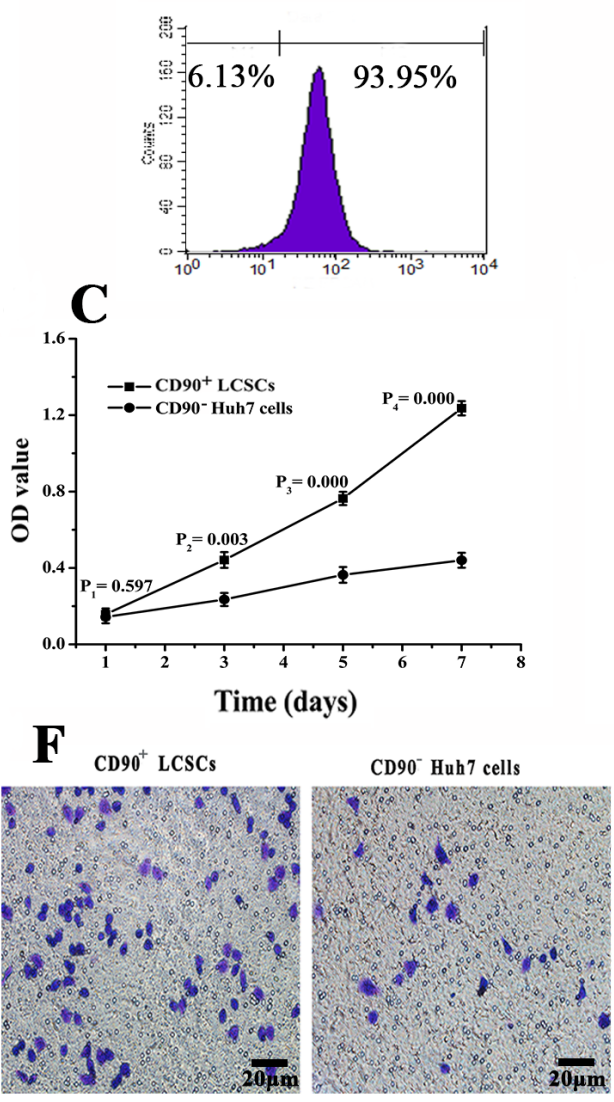

D
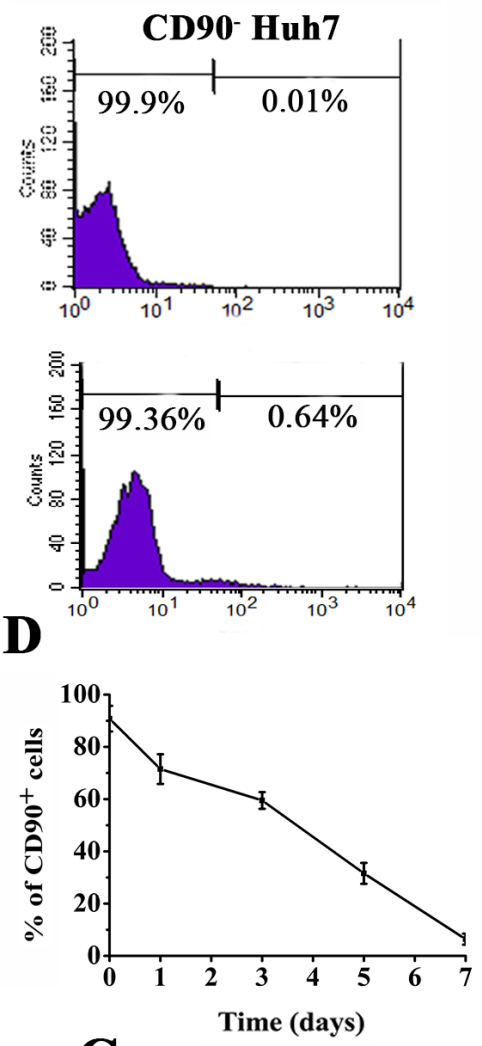

G

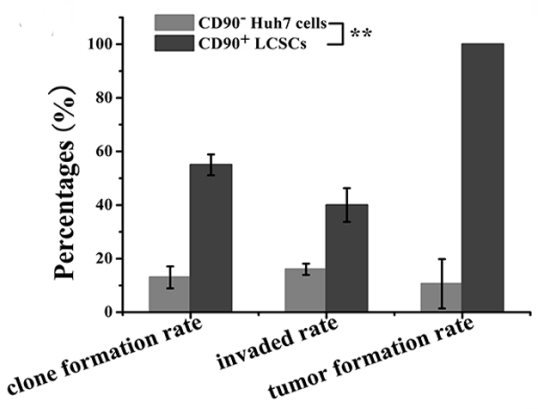

I

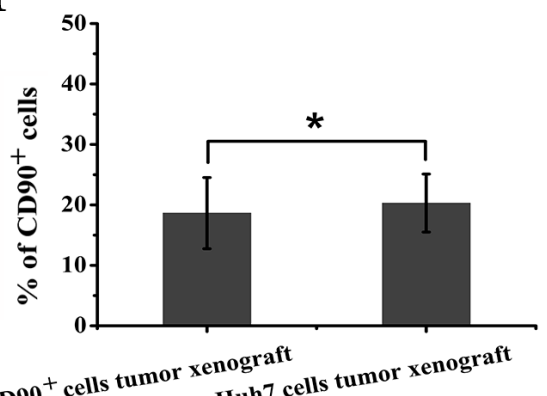

Figure 3: The stem characteristics of LCSCs. A. The expression rates of CD90 in unsorted, sorted positive and sorted negative cells. B. Morphology of LCSCs spheroids after maintained in DMEM/F12 medium for 7 days (The bar $=20 \mu \mathrm{m}$ ). C. Cell proliferation assay (mean $\pm \mathrm{SD}, n=3$ ). D. Cell differentiation assay (mean $\pm \mathrm{SD}, n=3$ ). E. Inhibition rate of CD90 LCSCs and CD90- Huh7 cells observed by CCK-8 assay (mean $\pm \mathrm{SD}, n=3$ ). F. Invasion assay of CD90 LCSCs and CD90 Huh7 cells (The bar $=20 \mu \mathrm{m}$ ). G. Clone formation rate, invaded rate and tumor formation rate (mean $\pm \mathrm{SD}, n=3$ ). H. Tumorigenic images of NOD/SCID mice on two month after injection. (The xenografts tumors were marked by black arrow, the bar $=200 \mu \mathrm{m}$ ). I. The percentages of CD90 cells in vivo. $* * P<0.05, * P>0.05$. Abbreviations: LCSCs, live cancer stem cells; DMEM/F12, Dulbecco's Modified Eagle Media: Nutrient Mixture F-12; CD90, cluster of differentiation 90; NOD/SCID, nonobese diabetic/severe combined immunodeficien. 
To evaluate the capacity of the CD90@TMs to promote the capture of $\mathrm{Fe}_{3} \mathrm{O}_{4}$ by $\mathrm{CD} 90^{+} \mathrm{LCSCs}$ in vitro, cells were stained with Prussian blue and imaged by optical microscopy (Figure 4D). The targeted groups exhibited deep blue staining compared to those incubated with non-targeted liposomes, $\mathrm{CD}^{-} 0^{-}$cells or pure $\mathrm{Fe}_{3} \mathrm{O}_{4}$,

$\mathbf{A}$
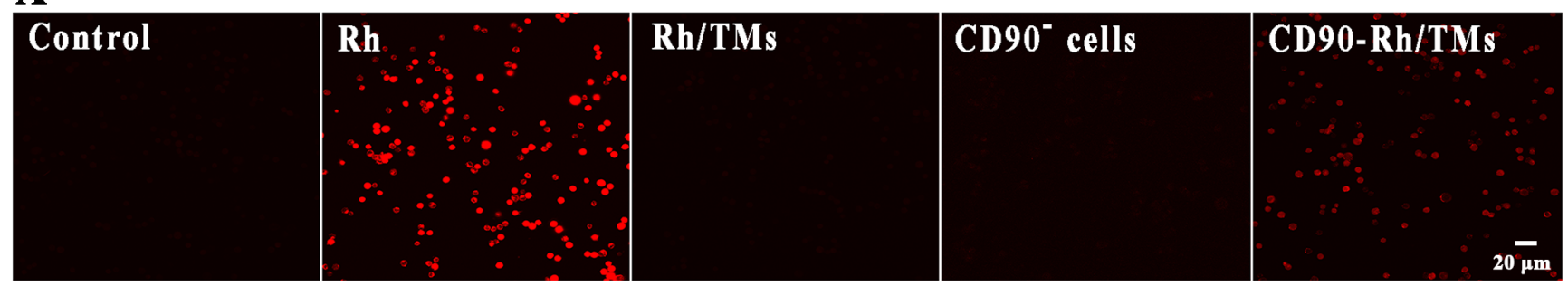

B

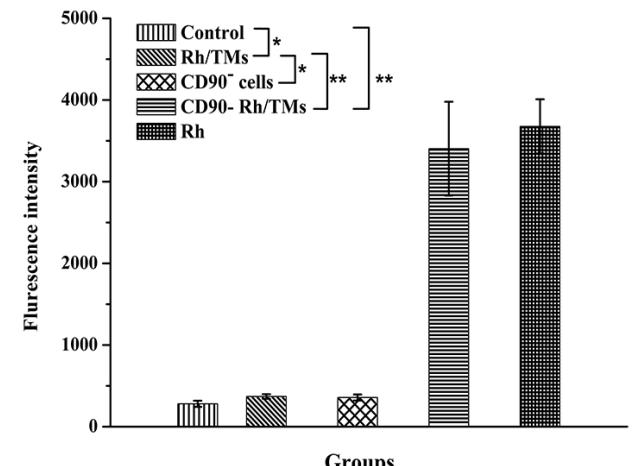

D

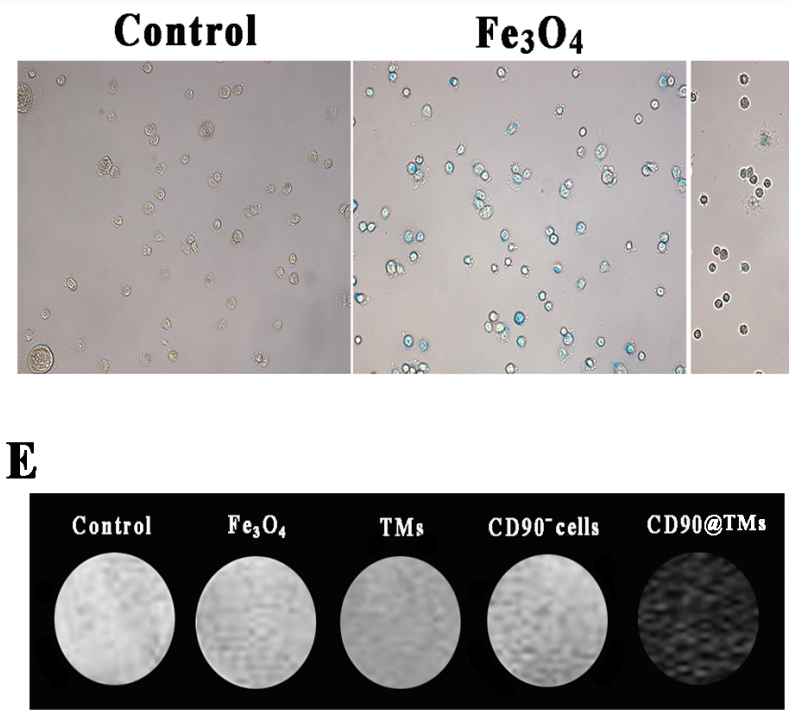

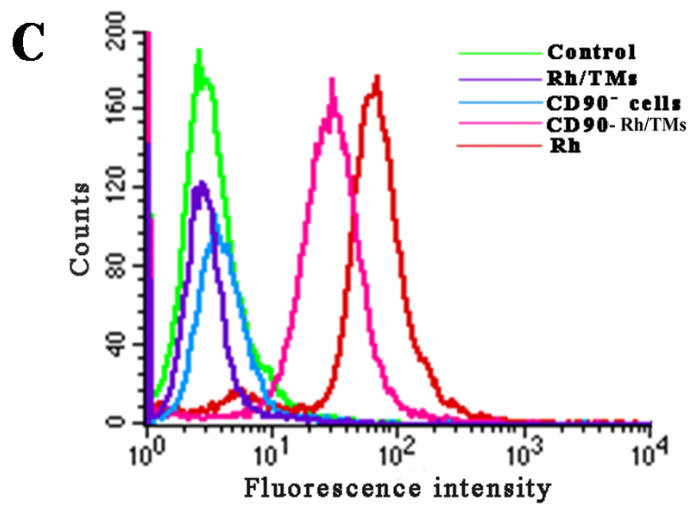

TMs
CD90@TMs
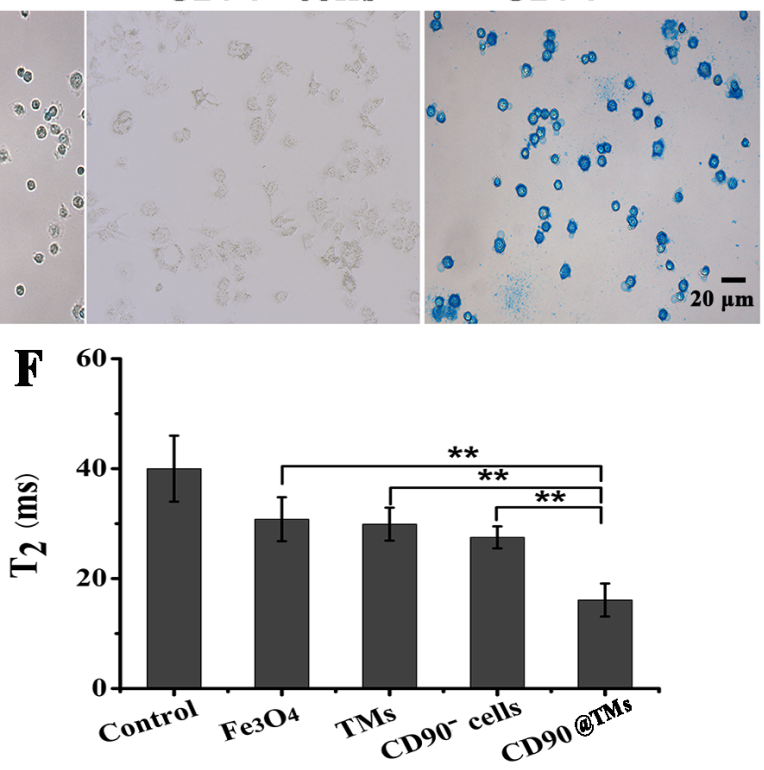

Figure 4: Specific targeting to CD90 ${ }^{+}$LCSCs with CD90-Rh/TMs. A. Internalization of control group, CD90-Rh/TMs group, $\mathrm{Rh}$ group, Rh/TMs group and CD90- Huh7 group detected by confocal microscopy, the bar $=20 \mu \mathrm{m}$. B. The fluorescence intensity of $\mathrm{Rh}$ detected by confocal microscopy (mean $\pm \mathrm{SD}, n=3$ ). C. Binding and internalization detected by flow cytometry of DMEM/F12 (control group), CD90-Rh/TMs (CD90- Rh/TMs group), free $\mathrm{Rh}(\mathrm{Rh}$ group), $\mathrm{Rh} / \mathrm{TMs}(\mathrm{Rh} / \mathrm{TMs}$ group) and CD90- Huh7 cells incubated with CD90-Rh/TMs(CD90- Huh7 group). D. Prussian blue staining of CD90+ LCSCs incubated with DMEM/F12 (control group), CD90@ TMs (CD90@TMs group), pure $\mathrm{Fe}_{3} \mathrm{O}_{4}$ ( $\mathrm{Fe}_{3} \mathrm{O}_{4}$ group), TMs (TMs group) and CD90-Huh7 cells incubated with CD90@TMs (CD90- Huh7 group), the bar $=20 \mu \mathrm{m}$. E. $\mathrm{T}_{2}$-weighted MRI images of control group, CD90@TMs group, $\mathrm{Fe}_{3} \mathrm{O}_{4}$ group, TMs group and CD90- Huh7 group. F. $\mathrm{T}_{2}$ relaxation time of control group, CD90@TMs group, $\mathrm{Fe}_{3} \mathrm{O}_{4}$ group, TMs group and CD90- Huh7 group (mean $\left.\pm \mathrm{SD}, n=3\right)$. ${ }^{2} P$ $>0.05$; $* * P 0.05$. Abbreviations: Rh, Lissamine rhodamine; TMs, thermosensitive magnetoliposomes; DMEM/F12, Dulbecco's Modified Eagle Media: Nutrient Mixture F-12; CD90, cluster of differentiation 90. 
indicating higher intracellular uptake of the $\mathrm{Fe}_{3} \mathrm{O}_{4}$ when modified with anti-CD90. Superparamagnetism $\mathrm{Fe}_{3} \mathrm{O}_{4}$ can reduce $T_{2}$ relaxation time and show low signal intensity on $\mathrm{T}_{2}$-weighted MRI. To determine whether the targeted magnetoliposomes can be used as an effective molecular imaging labeling agent via MRI, CD90 ${ }^{+}$LCSCs were treated with CD90@TMs, TMs and pure $\mathrm{Fe}_{3} \mathrm{O}_{4}$ for $60 \mathrm{~min}$. The results indicated that MRI signal intensity of the nontargeted group, pure $\mathrm{Fe}_{3} \mathrm{O}_{4}$ group and $\mathrm{CD} 90^{-}$cells group was sufficiently stronger than that of the targeted group (Figure $4 \mathrm{E}$ ). The $\mathrm{T}_{2}$ relaxation time of the three groups was shown in Figure 4F. The $\mathrm{T}_{2}$ relaxation time of CD90 LCSCs incubated with CD90@TMs was significantly lower than those of the cells incubated with non-targeted magnetoliposomes and pure $\mathrm{Fe}_{3} \mathrm{O}_{4}$ and the negative control cells and CD90- cells $(p<0.05)$. These results suggest that targeted magnetoliposomes taken up by the $\mathrm{CD}^{+} 0^{+}$LCSCs low the MRI signal intensity of the cells
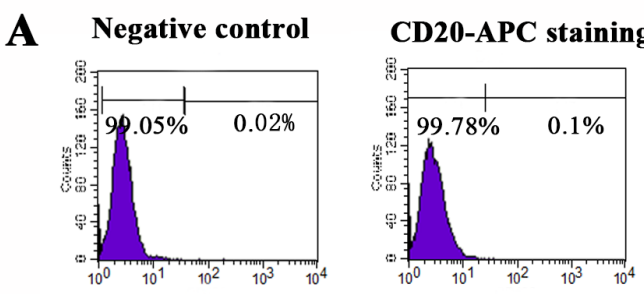

B
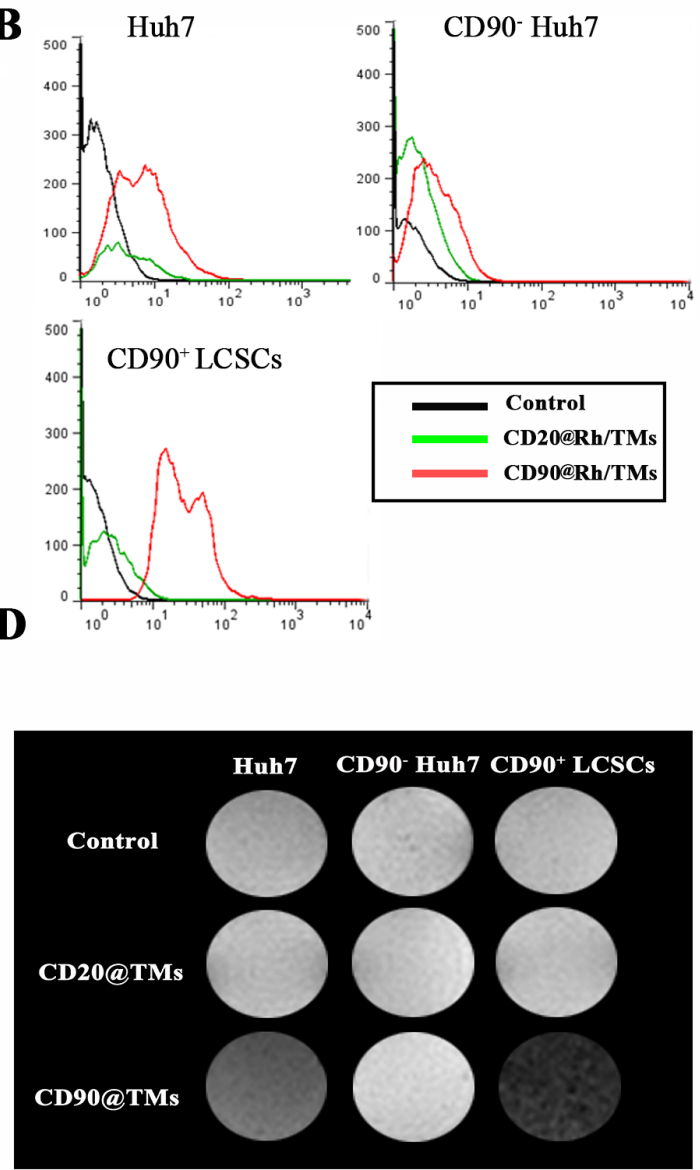

C

Huh7 CD90 Huh7 CD90 LCSCs

CD20@Rh/TMs

CD90@Rh/TMs
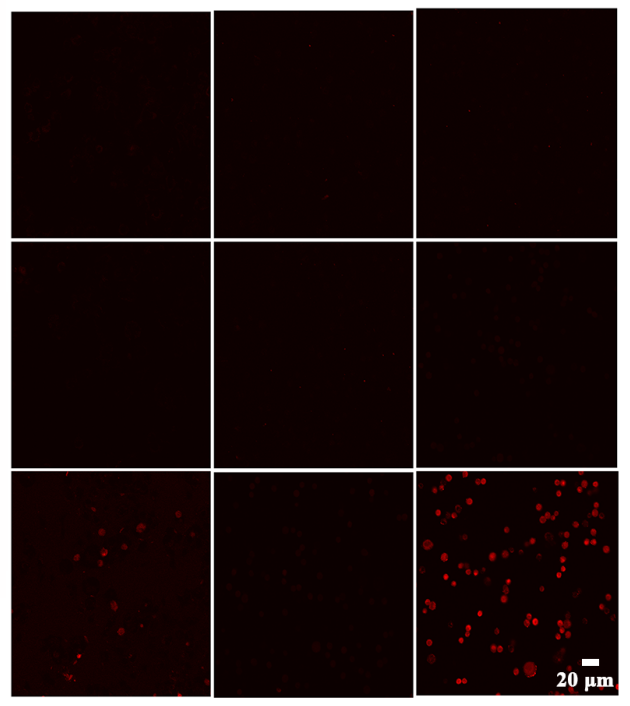

$\mathbf{E}$

Huh7

CD90 Huh7 CD90 ${ }^{+}$LCSCs

CD20@TMs
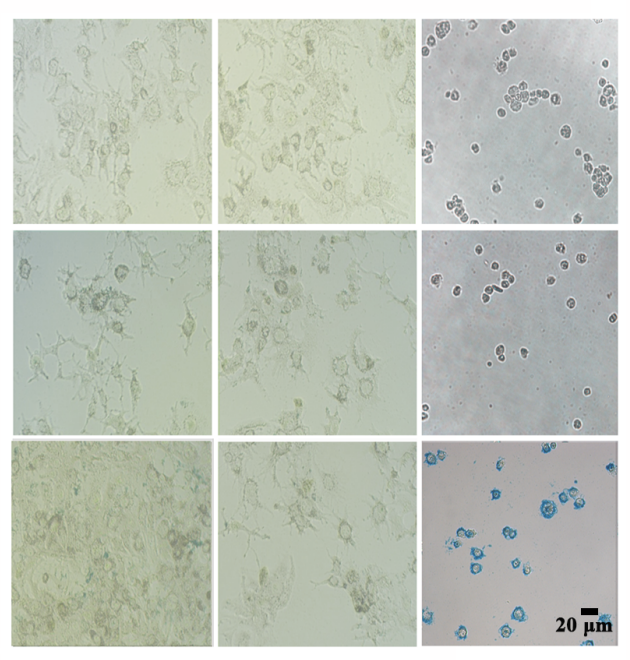

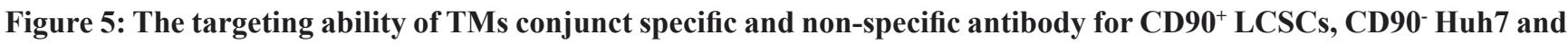
Huh7. A. The expression level of CD20 in Huh7. B. Binding and internalization of Rh detected by flow cytometry. C. Internalization of Rh detected by confocal microscopy, the bar $=20 \mu \mathrm{m}$. D. $\mathrm{T}_{2}$-weighted MRI images of CD90 ${ }^{+}$LCSCs, CD90- Huh7 and Huh7. E. Prussian blue staining of CD90 ${ }^{+}$LCSCs, CD90- Huh7 and Huh7, the bar $=20 \mu \mathrm{m}$. Abbreviations: Rh, Lissamine rhodamine; TMs, thermosensitive magnetoliposomes; DMEM/F12, Dulbecco's Modified Eagle Media: Nutrient Mixture F-12; CD90, cluster of differentiation 90. 
on $\mathrm{T}_{2}$ weight sequence, thereby enabling effective MRI detection of cancer cells in vitro.

The B-cell antigen CD20 is expressed on normal B cells and nearly all B-cell lymphomas. As it was shown in Figure 5A, there was nearly no expression of CD20 on the surface of Huh7. Hence, anti-CD20 MAb conjunct TMs (CD20@TMs) was chosen as a non-specific target group or irrelevant antibody target group to detect the specific cellular uptake of the CD90@TMs. The uptake with $\mathrm{CD} 90-\mathrm{Rh} / \mathrm{TMs}$ and $\mathrm{CD} 20-\mathrm{Rh} / \mathrm{TMs}$ using sorted positive, sorted negative and unsorted cells was observed by confocal microscopy. The fluorescence intensity of $\mathrm{Rh}$ in $\mathrm{CD}^{+} 0^{+}$cells group cultured with $\mathrm{CD} 90-\mathrm{Rh} / \mathrm{TMs}$ was higher than that of the other group(Figure 5B and Table 1), which was consistent with the flow cytometry results (Figure 5C). The fluorescence intensity in Huh7 cells group cultured with CD90-Rh/TMs was slightly higher than that in the control group. The reason may be that there are still about $6 \%$ CD90 ${ }^{+}$LCSCs in the Huh7 cells.
The difference among the control group, sorted positive, sorted negative and unsorted cells cultured with CD20$\mathrm{Rh} / \mathrm{TMs}$ had not statistical significance $(P>0.05)$. The capture of $\mathrm{Fe}_{3} \mathrm{O}_{4}$ by $\mathrm{CD} 90^{+}$LCSCs in vitro was detected by MRI (Figure 5D and Table 2) and Prussian blue staining (Figure 5E). The results showed that the content of $\mathrm{Fe}_{3} \mathrm{O}_{4}$ was highest in CD90+ LCSCs cultured with CD90@TMs compared to other groups. It suggested that CD90@TMs was a good target carrier for the delivery of the drug to CD90 ${ }^{+}$LCSCs.

It is worth noting that although in this experiment the CD90@TMs in vitro can bind to the CD90+ stem cells, whether it will be swallowed by macrophages reside in the reticuloendothelial system (RES ) of liver is yet to know. We further performed the phagocytosis experiments to confirm whether the liposome is taken up by macrophages in vitro, and by the liver in vivo. It is straightforward to acquire $T_{2}$ maps in non-tumor bearing mice prior to and following liposome administration. As shown in Figure
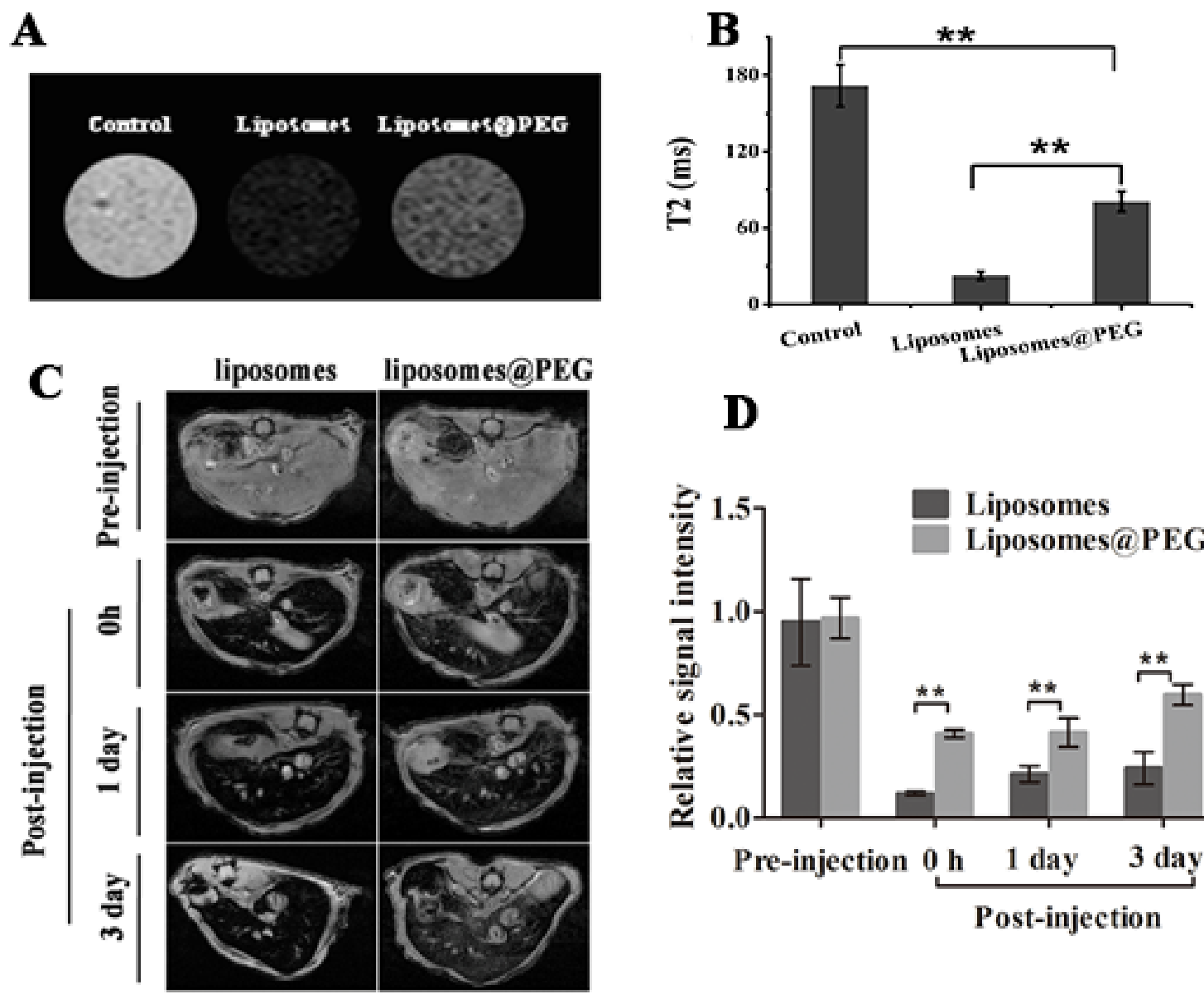

\section{D}

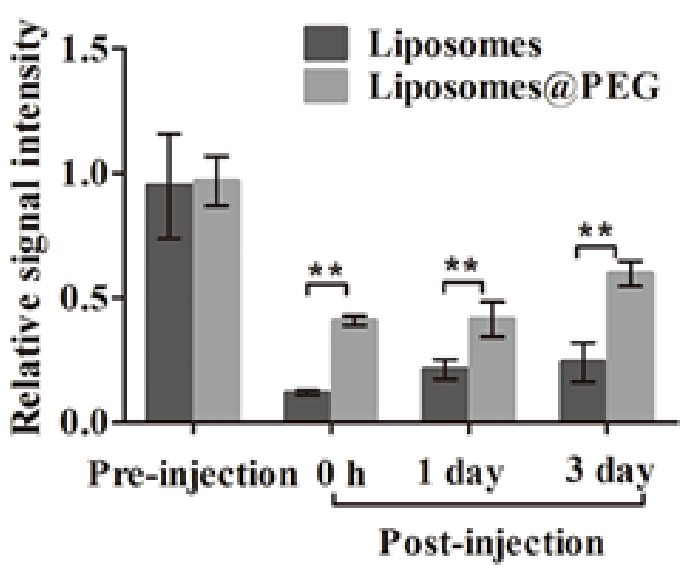

Figure 6: Non-specific uptake experiments in vitro and in vivo. A. Non-specific uptake assay by RAW264.7 cells in vitro. B. $\mathrm{T}_{2}$ value of the RAW264.7 cells (mean $\pm \mathrm{SD}, n=3$ ). C. Non-specific uptake assay by liver in vivo. D. Relative signal intensity of the liver. The $\mathrm{T}_{2}$ values were calculated and recorded as the mean \pm standard deviation $(n=3) . * * P<0.05$. 
Table 3: Apoptosis rate (\%) of the Huh7 cells, CD90+ LCSCs and CD90- Huh7 cells

\begin{tabular}{|l|l|l|l|l|}
\hline & $\begin{array}{l}\text { Control } \\
(\overline{\mathbf{x}} \pm \mathbf{S}, \boldsymbol{n}=\mathbf{3})\end{array}$ & $\begin{array}{l}\mathbf{1 0 m i n} \\
(\overline{\mathbf{x}} \pm \mathbf{S}, \boldsymbol{n}=\mathbf{3})\end{array}$ & $\begin{array}{l}\mathbf{3 0 m i n} \\
(\overline{\mathbf{x}} \pm \mathbf{S}, \boldsymbol{n}=\mathbf{3})\end{array}$ & $\begin{array}{l}\mathbf{1 h} \\
(\overline{\mathbf{x}} \pm \mathbf{S}, \boldsymbol{n}=\mathbf{3})\end{array}$ \\
\hline Huh7 & $3.8 \pm 2.8$ & $3.1 \pm 0.6^{*}$ & $18.3 \pm 3.8^{*}$ & $23.8 \pm 3.2^{*}$ \\
\hline CD90 ${ }^{+}$LCSCs & $4.4 \pm 3.1$ & $4.4 \pm 0.6^{*}$ & $17.1 \pm 2.7^{*}$ & $24.8 \pm 4.9 *$ \\
\hline CD90- Huh7 & $2.6 \pm 2.4$ & $4.7 \pm 0.5^{*}$ & $18.2 \pm 2.8^{*}$ & $25.9 \pm 3.6^{*}$ \\
\hline
\end{tabular}

Notes: Data are presented as means \pm standard deviation. Each experiment was repeated at least three times. ${ }^{*}$ Comparisons between the three groups in each time, $P>0.05$

Table 4: Apoptosis rate (\%) of the CD90+ LCSCs

\begin{tabular}{|l|l|}
\hline Group & $\begin{array}{l}\text { Apoptosis rate } \\
(\overline{\mathbf{x}} \pm \mathbf{S}, \boldsymbol{n}=\mathbf{3})\end{array}$ \\
\hline Control & $4.1 \pm 1.1$ \\
\hline TMs alone & $4.5 \pm 2.4$ \\
\hline Anti-CD90 mAb & $5.2 \pm 1.4$ \\
\hline Anti-CD20 mAb & $3.8 \pm 2.9$ \\
\hline CD90@TMs alone & $5.7 \pm 1.6$ \\
\hline TMs+AMF & $19.9 \pm 6.4^{* *}$ \\
\hline CD90@TMs+AMF & $66.3 \pm 6.9^{* *}$ \\
\hline
\end{tabular}

Notes: Data are presented as means \pm standard deviation. Each experiment was repeated at least three times. ** Comparisons between the experimental groups and the control group, $P<0.05$.

6A, liposomes group displayed lower $\mathrm{T}_{2} \mathrm{WI}$ signal intensity than liposomes@PEG after co-incubated with the same concentration of $\mathrm{Fe}_{3} \mathrm{O}_{4}$. The $\mathrm{T}_{2}$ relaxation time (Figure 6B) between liposome group and liposomes@ PEG group showed significant statistically difference $(P<0.05)$, which demonstrated that PEG-modified liposomes could effectively reduce the phagocytosis of macrophages. In vivo MRI showed that $\mathrm{T}_{2} \mathrm{WI}$ (Figure 6C) intensity of liver tissue decreased obviously at different time points both in liposomes group and liposomes@ PEG group. However, the relative signal intensity (Figure 6D) of liposomes group was significantly lower than liposomes@PEG group after injection $(P<0.05)$. Starting from $0 \mathrm{~h}$, the $\mathrm{T}_{2}$ relaxation time at different time points had statistical difference between liposomes group and liposomes@PEG group $(P<0.05)$. This indicated that PEG-modified liposomes could decrease the non-specific uptake of macrophage in liver tissue remarkably, increase the time length of in vivo cycle of liposome and thus, increase the chance to combine with target cells. This provided powerful basis for in vivo imaging and therapy.

When the micro particle carriers of the drug were delivered into the systemic circulation, they were easily engulfed by the macrophage in RES [28]. Most of macrophages reside in the blood-rich RES system such as liver, lung, spleen and lymph nodes which are the targets of passive targeting drugs. However, once the drug does not target on RES system, phagocytosis of RES system would interfere with the effect of drug targeting. Therefore, avoiding phagocytosis of RES system has become a key subject in drug targeting. Liposome is a kind of lipid vesicle with the structure of phospholipid bilayer, and the aqueous phase core inside it can entrap many kinds of chemical drugs [29]. Because their membrane component has good compatibility with living tissue, liposome has currently been widely applied in medical field as a kind of drug delivery system. With PEG, a hydrophilic polymeric substance, modifying the surface of liposome, the opsonization of plasma components can be blocked, which markedly decreases the RES system, for example in liver, spleen and so on, to engulf liposome.

\section{The sensitivity of CD90 ${ }^{+}$LCSCs, CD90- Huh7 cells and $\mathrm{Huh} 7$ cells to magnetic hyperthermia}

Magnetic fluid hyperthermia is an effective procedure for tumor therapy. It is invariably induced by an AMF induction-heating device. Previous studies of magnetic fluid hyperthermia showed that the therapeutic effects could be strengthened by combination with radiotherapy and chemotherapy [30]. Magnetic fluid hyperthermia has been used to treat various cancers, such as breast cancer and liver cancer, and the effects have been well documented [31, 32]. However, the effect of magnetic fluid hyperthermia on LCSCs is unknown. The purpose of this study was to evaluate the sensitivities of CD90 ${ }^{+}$LCSCs, CD90- Huh7 cells and Huh7 cells to TMsmediated magnetic hyperthermia in vitro. The cells were heated using TMs to a predefined temperature $\left(44^{\circ} \mathrm{C}\right)$ in 
an AMF for $10 \mathrm{~min}, 30 \mathrm{~min}$ and $1 \mathrm{~h}$. Changes in viability according to heating time were determined. As shown in Figure 7A, CD90 ${ }^{+}$LCSCs, Huh7 cells and CD90 Huh7 cells exhibited identical sensitivities to magnetic fluid hyperthermia. The inhibition rate of CD90 ${ }^{+} \mathrm{LCSCs}$ after heating for $10 \mathrm{~min}$ was $3.2 \pm 0.7 \%$ and there was no significant difference among CD90 ${ }^{+}$LCSCs, Huh7 and CD90 cells group $(P>0.05)$. There was also no significant difference among the three groups when the heating time was $30 \mathrm{~min}$ and $1 \mathrm{~h}(P>0.05)$. The apoptosis rate of Huh7, CD90 ${ }^{+}$LCSCs and CD90- Huh7 cells was $3.1 \pm 0.6 \%, 4.4 \pm 0.6 \%$ and $4.7 \pm 0.5 \%$ when heating for $10 \mathrm{~min}, 18.3 \pm 3.8 \%, 17.1 \pm 2.7 \%$ and $18.2 \pm 2.8 \%$ when heating for $30 \mathrm{~min}, 23.8 \pm 3.2 \% 24.8 \pm 4.9 \%$ and $25.9 \pm 3.6 \%$ when heating for $1 \mathrm{~h}$, respectively. (Figure $7 \mathrm{~B}$ and Table 3). There was no difference existed among CD90+ LCSCs, CD90- Huh7 cells and Huh7 cells group. These results indicated that, unlike chemotherapy and radiotherapy, CD90 ${ }^{+}$LCSCs showed identical sensitivity to magnetic fluid hyperthermia compared with CD90- Huh7 cells and Huh7 cells. This finding is consistent with a previous report [33]. Meanwhile, our data suggested that TMsmediated magnetic hyperthermia can effectively reduce the number of CD90+ LCSCs. The result also indirectly suggests that magnetic hyperthermia is an effective therapy for patients resistant to chemotherapy or those unable to undergo radiotherapy for liver cancer.

\section{Targeted hyperthermia using CD90@TMs for CD90 ${ }^{+}$LCSCs in vitro}

Magnetic particle can decrease cell viability by targeted intracellular hyperthermia or by some other
$\mathbf{A}$
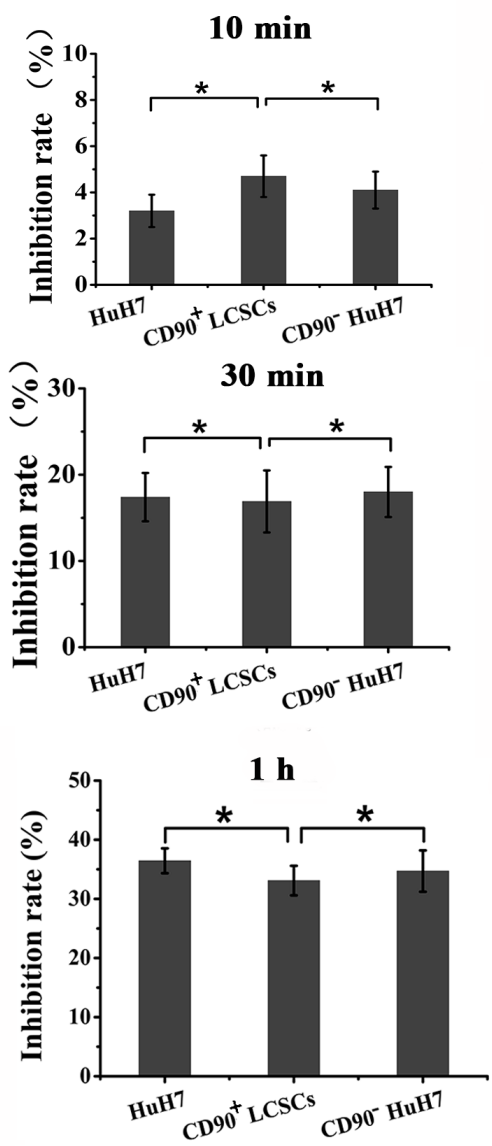

B

Unexposed AMF

Exposed AMF

$10 \mathrm{~min}$

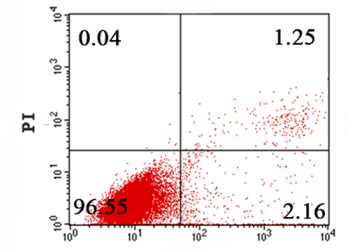

Huh7
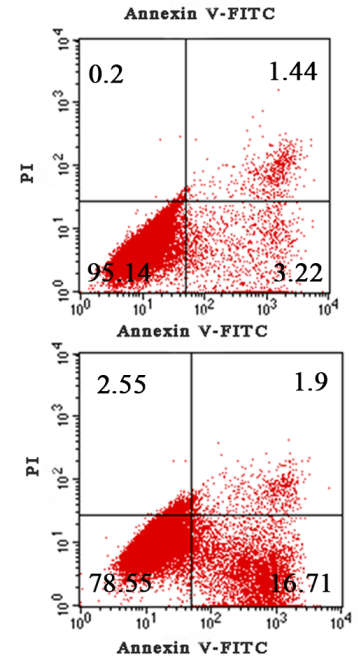

Exposed AMF

$30 \mathrm{~min}$

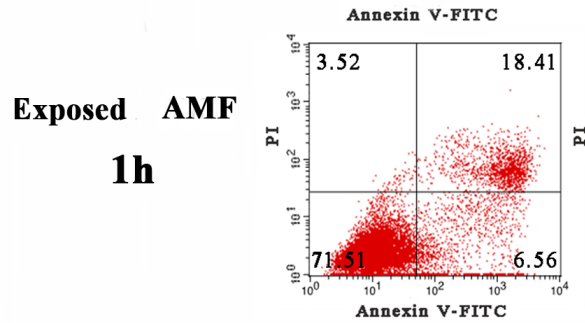

$\mathrm{CD90}^{+} \mathrm{LCSCs}$

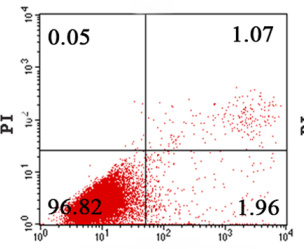

Annexin V-FITC
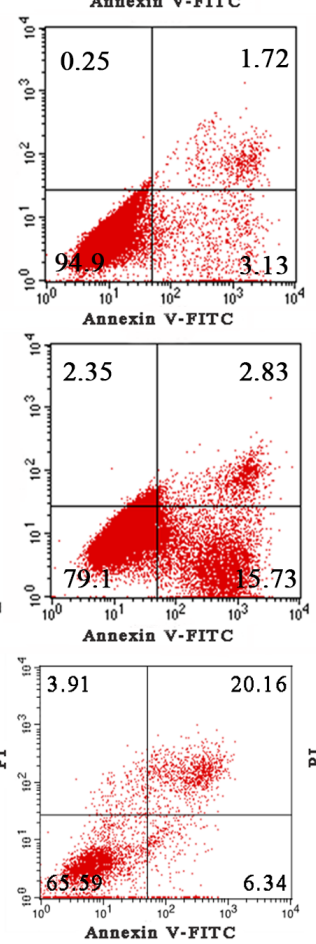

CD90- Huh7

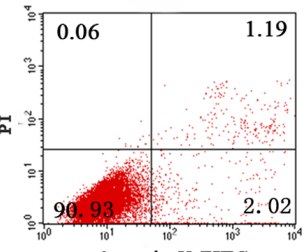

Annexin V-FITC
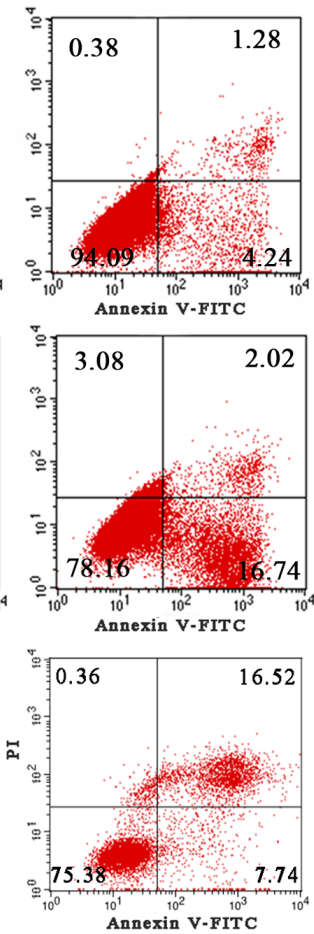

Figure 7: The sensitivity of $\mathrm{CD}^{+}$LCSCs, CD90- Huh7 cells and Huh 7 cells to magenatic hyperthermia. A. The sensitivity of CD90 ${ }^{+}$LCSCs, CD90- Huh7 cells and Huh 7 cells to magenatic hyperthermia observed by MTT assay (mean $\pm \mathrm{SD}, n=3$ ). B. The sensitivity of CD90 ${ }^{+}$LCSCs, CD90- Huh7 cells and Huh 7 cells to magenatic hyperthermia observed by annexin-V- FITC/PI affinity assays. Abbreviations: TMs, thermosensitive magnetoliposomes; LCSCs, live cancer stem cells; mAb, monoclonal antibody; PI, propidium iodide; FITC, fluorescein isothiocyanate isomer I; MTT, 3-(4,5)-dimethylthiahiazo (-z-y1)-3,5-di- phenytetrazoliumromide; CD90, cluster of differentiation 90; TEM, transmission electron microscope. 
mechanism that is SAR/field strength dependent [34]. In assays of hyperthermia sensitivity, TMs-mediated hyperthermia treated $\mathrm{CD} 90^{+} \mathrm{LCSC}$ resulted in a inhibition rate of $33.1 \pm 2.3 \%$. We next investigated whether the targeted magnetoliposomes, CD90@TMs, could kill CD90 ${ }^{+}$LCSCs more effectively than TMs. As shown in Figure $8 \mathrm{~A}$, the inhibition rate of the targeted hyperthermia group using CD90@TMs was increased to $70.57 \pm 4.1 \%$. However, non-targeted hyperthermia under identical conditions increased the inhibition rate to $29.21 \pm 3 \%$ while the anti-CD90, anti-CD20, TMs and CD90@TMs not exposure to AMF nearly showed no influence on the growth of the CD90 ${ }^{+}$LCSCs compared with control cells incubated with DMEM/F12. Thus, targeted hyperthermia was more effective in terms of inhibiting cell proliferation than non-targeted hyperthermia $(P<0.05)$.

A higher level of magnetic particle uptake by cell could contribute to an increase in intracellular hyperthermia leading to decrease cell viability [34]. To confirm that CD90@TMs were more effective in killing CD90 ${ }^{+}$LCSCs than non-target TMs, apoptosis was analyzed by flow cytometry (Figure 8B and Table 4). The proportion of apoptosis events in $\mathrm{CD} 90^{+}$ LCSCs treated with CD90@TMs and TMs exposed to magnetic hyperthermia were $66.3 \pm 6.9 \%$ and $19.9 \pm 6.4 \%$, respectively. Similar to the 3-(4, 5-dimethyl2-thiazolyl)-2, 5-diphenyl-2-H-tetrazolium bromide (MTT) assay results, anti-CD90 targeted hyperthermia resulted in a 3.3-fold higher apoptosis rate compared to non-targeted hyperthermia $(P<0.05)$. The proportions of cells in apoptosis stage following incubation with DMEM, anti-CD90, anti-CD20, TMs and CD90@TMs were $4.1 \pm 1.1 \%, 4.5 \pm 2.4 \%, 3.8 \pm 2.9 \%, 5.2 \pm 1.4 \%$, and $5.7 \pm 1.6 \%$, respectively. This indicated that anti-CD90, anti-CD20, TMs and CD90@TMs alone were not toxic to CD90 ${ }^{+}$LCSCs.

Cell ultrastructure changes and the distribution of the $\mathrm{Fe}_{3} \mathrm{O}_{4}$ nanoparticles at the cellular level were observed by TEM. Because the groups of anti-CD90, TMs and CD90@TMs alone showed no toxic to CD90+ LCSCs,
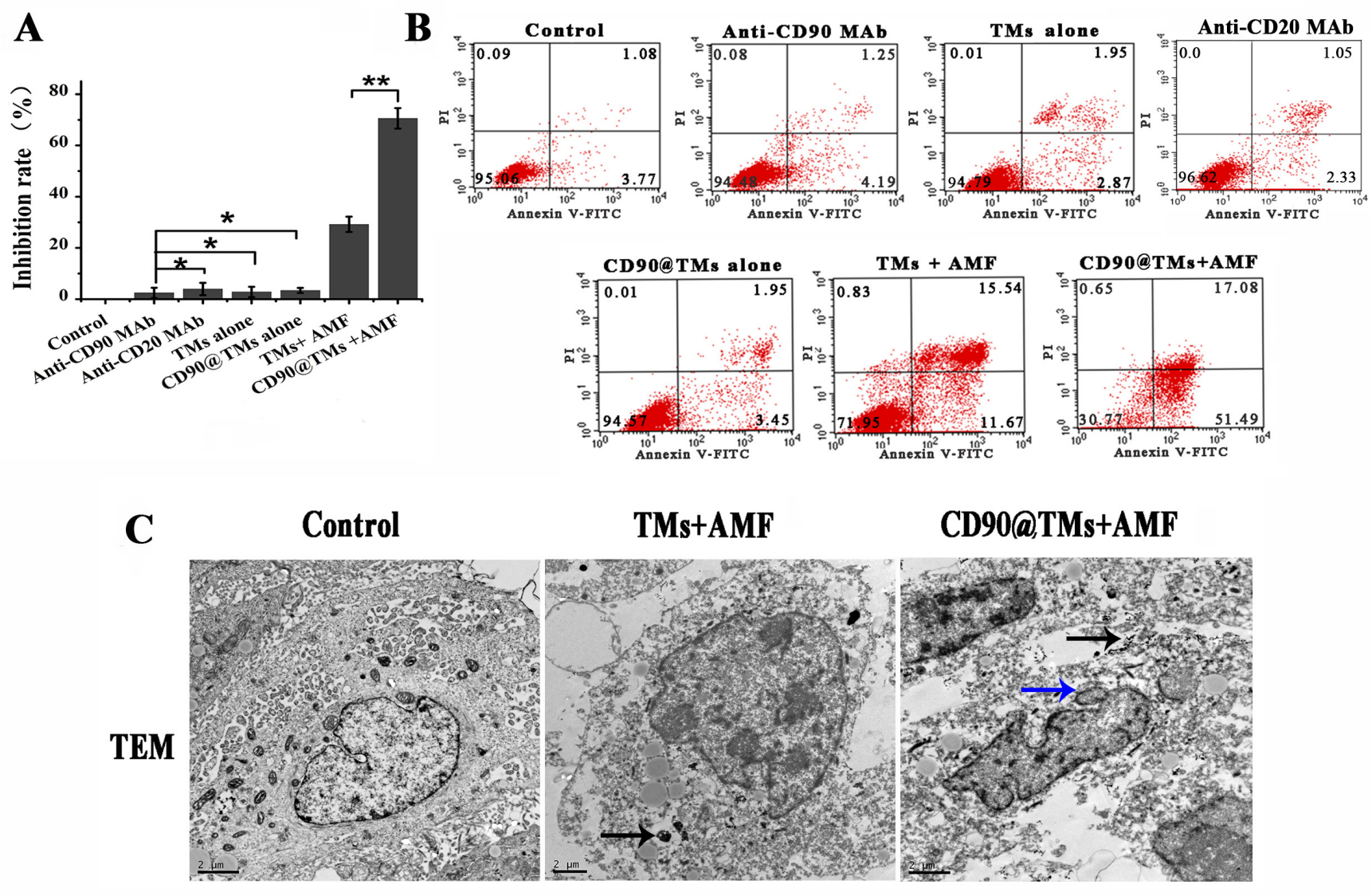

Figure 8: Targeted hyperthermia using CD90@TMs for CD90 ${ }^{+}$LCSCs. A. Surviving rate of the CD90 $0^{+}$CSCs observed by MTT assay (mean $\pm \mathrm{SD}, n=3$ ). B. Apoptosis of the CD90 LCSCs. $* P>0.05 ; * * P<0.05$. C. Cell ultrastructure changes were observed by TEM. (The black arrows stand for the magnetic nanomaterial; the blue arrows stand for the nuclear morphology of cell apoptosis; the bar= $2 \mu \mathrm{m})$. Abbreviations: TMs, thermosensitive magnetoliposomes; LCSCs, live cancer stem cells; mAb, monoclonal antibody; PI, propidium iodide; FITC, fluorescein isothiocyanate isomer I; MTT, 3-(4,5)-dimethylthiahiazo (-z-y1)-3,5-di- phenytetrazoliumromide; CD90, cluster of differentiation 90; TEM, transmission electron microscope. 
we only observed the distribution of the $\mathrm{Fe}_{3} \mathrm{O}_{4}$ and cell changes in the group of control, TM+AMF and CD90@ TMs+AMF by TEM. Figure $8 \mathrm{C}$ gave an impression of the particle uptake into the CD90 ${ }^{+}$LCSCs in TMs+AMF and CD90@TMs+AMF groups (black arrows). The nuclear membrane in the control group was clear with intact nuclei. In contrast, in hyperthermia group, the nucleus became deformative and the nuclear membrane fractured. The typical morphological changes of apoptosis included chromatin condensation and aggregation at the periphery of the nucleons could be seen in the CD90@TMs+AMF group (blue arrow). The results mean that hyperthermia can killed CD90 $0^{+}$LCSCs. The effect of target hyperthermia is superior to non-targeted hyperthermia.

There is no established method of determining the effects of hyperthermia on CSCs. Therefore, we investigated the characteristics of CSCs, including drug resistance, colony formation and invasion, as well as tumorigenic ability. The MTT and apoptosis assays showed that anti-CD90, anti-CD20, TMs alone and
CD90@TMs alone exhibited no toxicity against CD90+ LCSCs. So, CD90@TMs and TMs mediated hyperthermia were chosen to detect the effect of target hyperthermia and non-target hyperthermia to drug resistance, colony formation invasion and tumor formation. CD90 $0^{+} \mathrm{LCSCs}$ derived from Huh7 cells treated with CD90@TMs mediated hyperthermia showed a marked decrease in colony formation rate and invasion rate compared to TMs-mediated hyperthermia (Figure 9A, 9B, 9C; $P<$ $0.05)$. IC50 of CD90@TMs $(3.7 \pm 0.2 \mu \mathrm{g} / \mathrm{mL})$ group was significant $(P<0.05)$ smaller than control group $(15.7 \pm 3$ $\mu \mathrm{g} / \mathrm{mL})$ and TMs group $(7.8 \pm 1.1 \mu \mathrm{g} / \mathrm{mL})$. Magnetic hyperthermia exposure inhibited the tumorigenic ability of CD90 ${ }^{+}$LCSCs, as $27.3 \pm 9.8 \%$ of the mice treated with TMs mediated hyperthermia and $78 \pm 19.1 \%$ treated with CD90@TMs mediated hyperthermia exhibited no tumors at 70 days after the injection (Figure 9D, 9E). Compared with TMs-mediated hyperthermia, CD90@TMs mediated hyperthermia showed a marked delay in tumor generation and decreased tumorigenesis and tumor volume (Figure

\section{A Control}

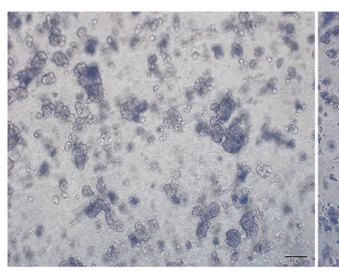

B Control
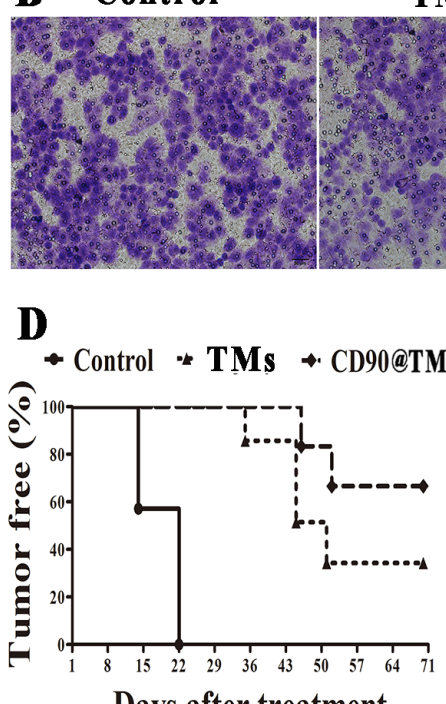

Days after treatment
TMs

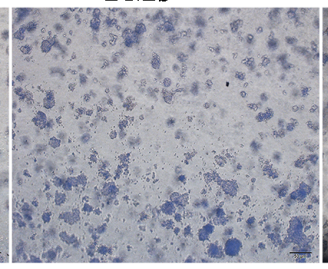

TMs

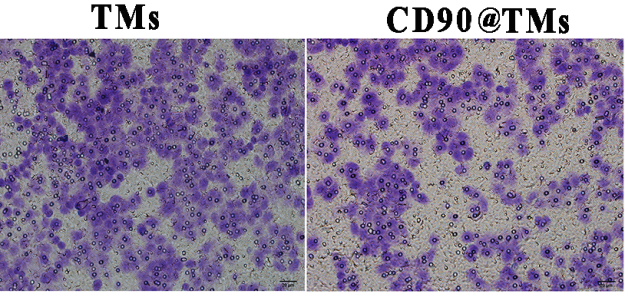

CD90@TMs

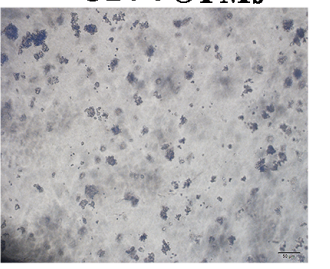

20

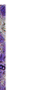

.
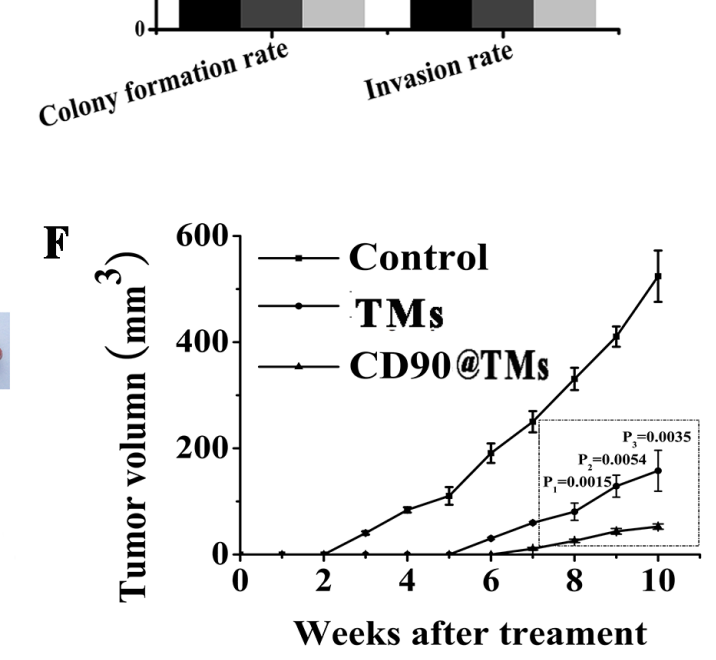

Figure 9: Effects of hyperthermia on the CD90 ${ }^{+}$LCSCs characteristic. A. Effect of different treatment methods on colony formation of CD $90^{+}$LCSCs (The bar $\left.=50 \mu \mathrm{m}\right)$. B. Effect of different treatment methods on invasion of CD90 LCSCs $(\mathrm{The}$ bar $=20 \mu \mathrm{m})$. C. Effect of different treatment methods on colony formation, invasion of CD90 $0^{+} \mathrm{LCSCs}$ (mean $\pm \mathrm{SD}, n=3$ ). D. Effect of different treatment methods on tumorigenic ability $(n=6)$. Kaplane-Meier plot showed that the oncogenicity of mice in the control group is significantly higher than that in TMs and CD90@TMs group $(p<0.05)$. E. Tumors morphology in different treatment methods. F. Effect of different treatment methods on tumor growth of CD90 ${ }^{+} \mathrm{LCSCs}$ (mean $\pm \mathrm{SD}, n=6$ ). ${ }^{*} P<0.05$. Abbreviations: TMs, thermosensitive magnetoliposomes; LCSCs, live cancer stem cells; CD90, cluster of differentiation 90; AMF, alternating magnetic field. 
$\mathbf{A}$

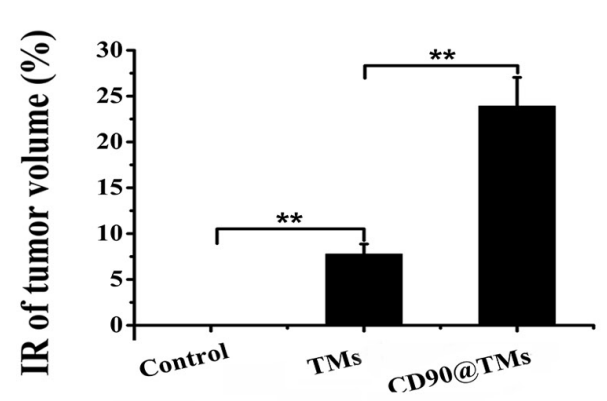

B

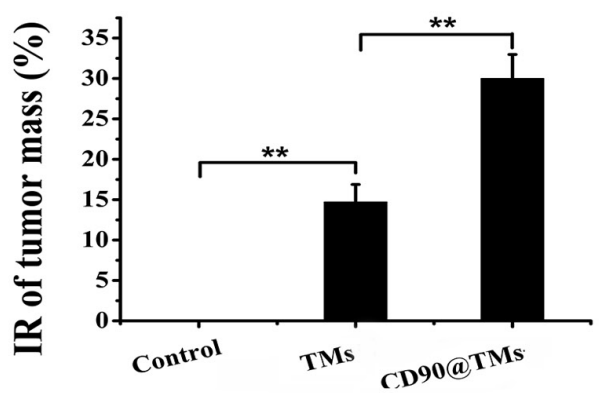

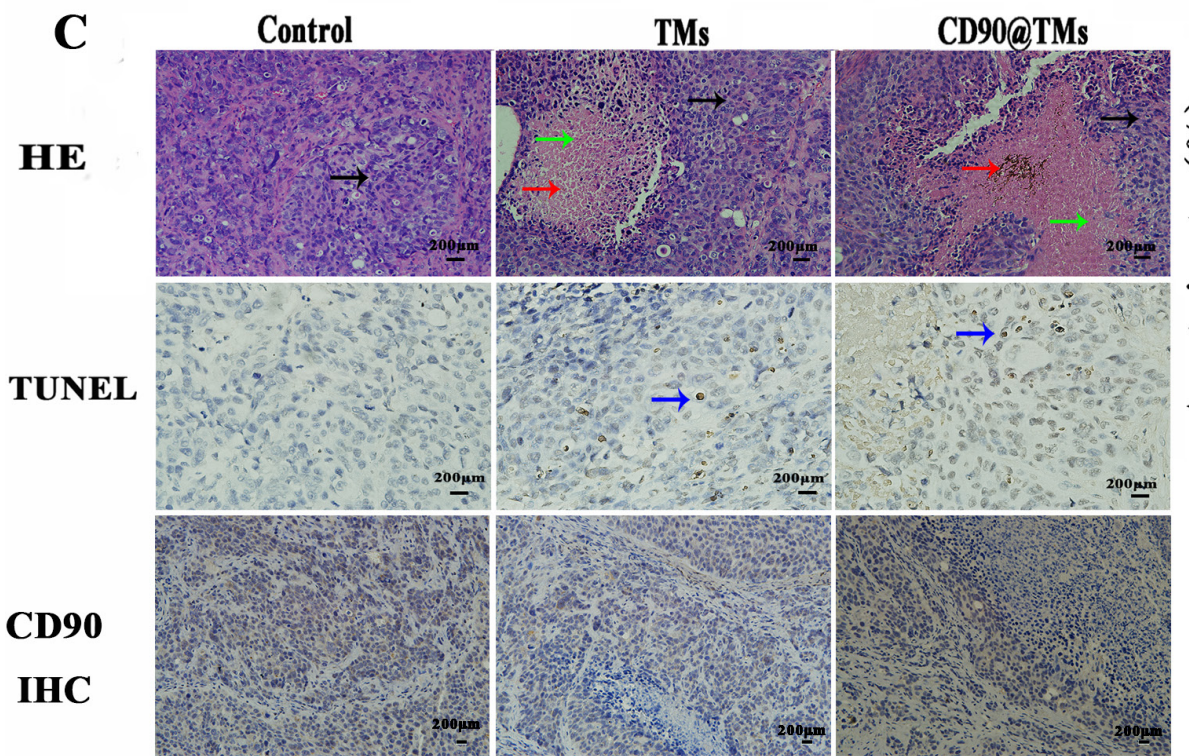

TUNEL $\mathbf{F}$

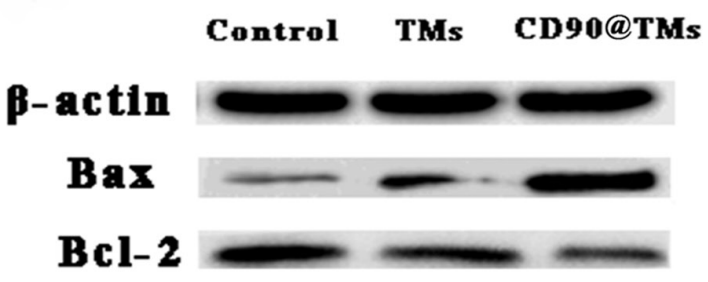

D
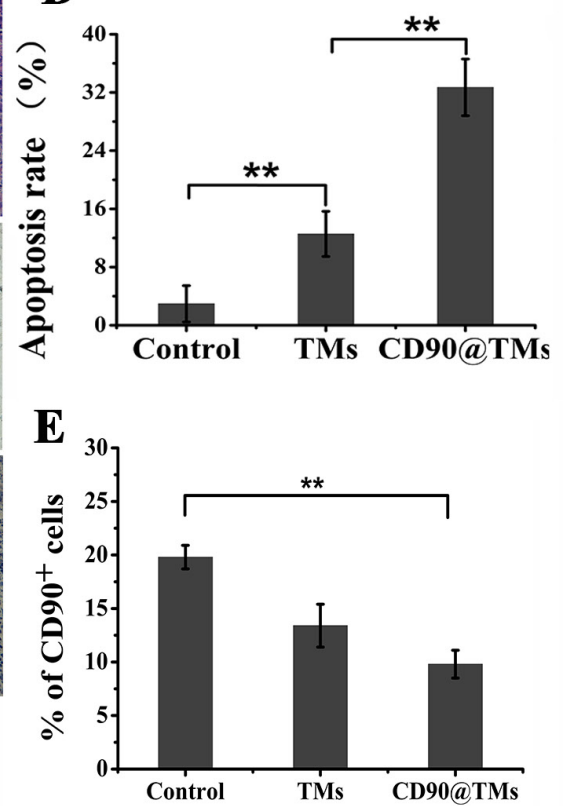

Figure 10: Effect of targeted hyperthermia on CD90 ${ }^{+}$LCSCs bearing mice. A. Inhibition rate of tumor volume in different experimental groups (mean $\pm \mathrm{SD}, n=6$ ). B. Inhibition rate of tumor mass in different experimental groups (mean $\pm \mathrm{SD}, n=6$ ). C. Tumor tissues of CD $90^{+}$LCSCs-bearing mice stained by HE staining, TUNEL staining and CD90 IHC staining assay (the black arrows stand for the tumor tissues; the green arrows stand for the necrosis and collapse of tumor cells; the red arrows stand for the magnetic nanomaterial, the blue arrows stand for the typical apoptosis characteristics), the bar $=200 \mu \mathrm{m}$. D. Apoptotic cells in tumor tissues of CD90 ${ }^{+}$LCSCsbearing mice (mean $\pm \mathrm{SD}, n=6$ ). To assess the fraction of apoptotic cells, the count of TUNEL-positive cells was calculated from five sections. ${ }^{* *} P<0.05$. E. CD90 ${ }^{+}$cells in tumor tissues after being treated. ${ }^{*} P<0.05$. F. Bax and Bcl-2 analysis by western blot. G. Relative density of Bax and Bcl-2. ${ }^{* *} P<0.05$. Abbreviations: IR, inhibition rate; TMs, thermosensitive magnetoliposomes; CD90, cluster of differentiation 90; HE, haematoxylin-eosin; TUNEL, terminal deoxynucleotidyl transferase-mediated dUTP-biotin nick end labeling; IHC, immunohistochemical. 
9D, 9F). This suggested that the CD90@TMs-mediated intracellular magnetic hyperthermia effectively reduced or, in some cases, eliminated scarce CSCs.

\section{Effect of targeted hyperthermia on CD90 ${ }^{+}$LCSCs- bearing mice}

Hyperthermia is a new and effective cancer treatment method that has gained popularity in recent years [35]. The ability of CD90@TMs to work in vivo was assessed in CD90 $0^{+}$LCSCs-bearing mice. The effect was assessed by determining tumor volume and mass over a treatment period of 7 days, and by HE staining at the end of the treatment period. The mice were divided into three groups: control group; TMs group and CD90@ TMs group. As shown in Figure 10A, the CD90@TMs group had the most significant reduction in tumor size compared to control $(P<0.05)$. The inhibition rate of tumor volume increased to $23.92 \pm 3.12 \%$ in the CD90@ TMs group and more than 2-fold in the TMs group. The tumor mass inhibit rate of the CD90@ TMs group was higher than those in the control group and TMs group (Figure 10B). The inhibition rates of tumor mass of the TMs group and CD90@TMs group were 14.7 $\pm 2.2 \%$ and $30.0 \pm 2.9 \%$, respectively. On day 7 , all mice were sacrificed. HE staining was performed. As shown in Figure $10 \mathrm{C}$, visible $\mathrm{Fe}_{3} \mathrm{O}_{4}$ sediment (red arrows) was found in the tumor tissues (black arrows) taken from thermotherapy groups and these sediments were surrounded by necrotic tumor cells (green arrows). The most severe damage occurred in the CD90@TMs group, which may explain why the highest decrease in tumor volume occurred in this group. To identify the cell apoptosis rate in vivo, terminal deoxynucleotidyl transferase-mediated dUTP-biotin nick end labeling (TUNEL) staining (Figure 10C, 10D) was performed. The largest number of TUNEL positive cells was found in the tumor tissues of the CD90@TMs group. A significant difference was detected between the CD90@ TMs group and the other groups $(P<0.05)$. Compared with TMs group, CD90 expression decreased more significantly in CD90@TMs group $(P<0.05$, Figure 10C, $10 \mathrm{E})$. Research on hyperthermia is lagging and further study of the underlying molecular mechanism is needed. It is known that apoptosis contributes to hyperthermiainduced tumor killing alone or when combined with other therapies [36]. Initiation of apoptosis directly regulates cell fate decisions and the ratio of Bcl-2 family members is a crucial modulating factor in the process [37]. For example, the ratio of $\mathrm{Bax} / \mathrm{Bcl}-2$ is a trigger of apoptosis [38]. Studies have shown that hyperthermia can induce apoptosis through the mitochondrial pathway, although how hyperthermia activates mitochondria remains unknown [39]. The ratio of Bax and Bcl-2 may play an important role in this regard [40], which was supported by Western blot results demonstrating that hyperthermia led to a down-regulation of the apoptosis suppression protein $\mathrm{Bcl}-2$ and up-regulation of Bax compared with the control group $(P<0.05$, Figure 10F, 10G). This suggested that hyperthermia could induce apoptosis by regulating the expression of the apoptosis-related proteins Bcl-2 and Bax during CSC-targeted therapy because the antiCD90 targeted hyperthermia group showed greater downregulation of Bcl-2 and an up-regulation of Bax compared to the TM-mediated magnetic hyperthermia group ( $P$ $<0.05)$. Above all, CD90@TMs is more effective in eradicating CD $90^{+}$LCSCs compared to TMs in vivo.

The isolation of CSCs based on stem cell surface markers provides an important tool for investigating the properties of LCSCs and has represents a potential molecular target for LCSC therapy [41]. Thymocytes, T-cells, fibroblasts, endothelial cells, neurons and LCSCs share common cell surface markers, which could result in damage to these cells if CD90 was used as a molecular target. However, magnetic fluid hyperthermia has the advantage of being able to precisely heat the tumor tissue. When $\mathrm{Fe}_{3} \mathrm{O}_{4}$ particles reach the tumor, a magnetic field induction-heating device is applied to heat the magnetic fluid taken up by the CD90 $0^{+}$LCSCs and minimize damage to normal tissues. Several studies have indicated that CSCs are resistant to conventional chemotherapy and radiotherapy. However, when such traditional therapies are combined with hyperthermia, this resistance could be reduced [42] or eliminated [43]. Furthermore, effective elimination of CSCs through hyperthermia has been reported by Sadhukha [13]. Thus, hyperthermia may be useful for the treatment of HCC through purging LCSCs.

These results describe the first use of hyperthermia to target and kill LCSCs. Our findings demonstrate that the CD90@TMs can effectively target LCSCs and show increased tumor cell killing efficacy compared with TMs in vitro and in vivo. This indicates that hyperthermia may be a promising modality for the control of human tumors.

\section{MATERIALS AND METHODS}

\section{Cells and animals}

Huh7 cells were purchased from the Institute of Biochemistry and Cell Biology (Shanghai Institute of Biological Sciences, Chinese Academy of Sciences). Cells were cultured in RPMI 1640 medium (Gibco, Grand Island, NY, USA) supplemented with $10 \%$ fetal bovine serum (FBS, Shanghai, China), $100 \mathrm{U} / \mathrm{mL}$ penicillin, and $100 \mathrm{mg} / \mathrm{mL}$ streptomycin and maintained at $37^{\circ} \mathrm{C}$ with $5 \% \mathrm{CO}_{2}$ in a humidified incubator. CD90 $0^{+} \mathrm{LCSC}$ were isolated from Huh7 cell lines through MACS and cultured with DMEM/F12 (1:1) (Gibco, NY, USA) containing 20 $\mu \mathrm{g} / \mathrm{L}$ recombinant human epidermal growth factor (hEGF), $20 \mu \mathrm{g} / \mathrm{L}$ basic fibroblast growth factor (bFGF) and 2\% B27 
in a low-adhesion culture bottle.

Nonobese diabetic/severe combined immunodeficien mice (NOD/SCID mice, male, 5 weeks old) were purchased from the vital river experimental animal technical co., LTD in Beijing, China. All the mice were maintained in the Sterile Barrier System of Medical School, Southeast University, China. All experiments involving animals were performed in compliance with the guidelines of the Animal Care Committee of Southeast University, Nanjing, China. All animals received humane care in compliance with the Principles of Laboratory Animal Care formulated by the National Society for Medical Research and the Guide for the Care and Use of Laboratory Animals prepared by the Institute of Laboratory Animal Resources and published by the National Institutes of Health (NIH Publication No. 86-23, revised 1996).

\section{Materials}

A MidiMACS starting kit was purchased from Miltenyi Biotec (Germany). Purified mouse anti-human CD90 was purchased from BD Pharmingen. Rh was purchased from Aladdin (Shanghai, China). DAPI Fluoromount- $\mathrm{G}^{\circledR}$ was purchased from Southern Biotech (Birmingham, USA). DPPC, PEG $_{2000}$-DSPE, and MAL$\mathrm{PEG}_{2000}$-DSPE were purchased from Lipoid (Germany). Dihydro-2(3H)-thiophenimine hydrochloride (Traut's reagent) was purchased from Sigma-Aldrich (St. Louis, USA). All solvents were of high-performance liquid chromatography grade.

\section{Preparation of CD90@TMs}

$\mathrm{Fe}_{3} \mathrm{O}_{4}$ was prepared as described by Li using chemical co-precipitation [44]. $56 \mathrm{mg}$ of DPPC, $6 \mathrm{mg}$ of Chol and $1 \mathrm{mg}$ of $\mathrm{PEG}_{2000}-\mathrm{DSPE}$ was dissolved in $6 \mathrm{~mL}$ of methanol and $3 \mathrm{~mL}$ of chloroform (v/v, 2:1) [45]. The lipids formed a homogeneous thin film following vacuum rotary evaporation at $42^{\circ} \mathrm{C} .10 \mathrm{~mL}$ of PBS buffer $(0.1 \mathrm{M}$, $\mathrm{pH}=7.4)$ mixed with $\mathrm{Fe}_{3} \mathrm{O}_{4}(2 \mathrm{mg} / \mathrm{mL})$ was added for 1 $\mathrm{h}$ to hydrate the solution and obtain TMs. $10 \mathrm{~mL}$ of PBS buffer $(0.1 \mathrm{M}, \mathrm{pH}=7.4)$ mixed with $10 \mathrm{mg} \mathrm{Rh}$ as a red fluorescent marker and $20 \mathrm{mg} \mathrm{Fe}{ }_{3} \mathrm{O}_{4}$ was added for an additional $1 \mathrm{~h}$ to obtained $\mathrm{Rh} / \mathrm{TMs}$. The liposomes were placed in a dialysis bag $(1000 \mathrm{Da})$ which was immersed in PBS buffer $(0.1 \mathrm{M}, \mathrm{pH}=7.4)$ to remove non-encapsulated $\mathrm{Rh}$. Finally, the non-encapsulated $\mathrm{Fe}_{3} \mathrm{O}_{4}$ was removed by centrifuge at $1500 \mathrm{rpm}$ for $20 \mathrm{~min}$ three times.

CD90@TMs were prepared as described previously using post-insertion $[46,47]$ with a slight modification. In brief, sulfhydryl was introduced to purified mouse antihuman CD90 $(1 \mathrm{mg})$ by incubating with $0.09 \mathrm{mg}$ of traut's reagent in $0.5 \mathrm{~mL}$ PBS buffer $(0.1 \mathrm{M}, \mathrm{pH}=8.0)$. Antihuman CD90-SH was incubated with liposomes of $4 \mathrm{mg}$ of Mal-PEG 2000 -DSPE and $13.6 \mathrm{mg}$ of $\mathrm{PEG}_{2000}-\mathrm{DSPE}$ (the initial molar ratio of PEG 2000 -DSPE relative to Mal$\mathrm{PEG}_{2000}$-DSPE was $4: 1$ ) at $4^{\circ} \mathrm{C}$ overnight in $4 \mathrm{~mL}$ of PBS $(0.1 \mathrm{M}, \mathrm{pH}=8.0)$. Non-conjugated Abs was removed by centrifuge at $12000 \mathrm{~g}$ for $20 \mathrm{~min}$ three times. Anti-human CD90-PEG ${ }_{2000}$-DSPE was then incubated with $36 \mathrm{mg}$ of TMs (DPPC) (the initial molar ratio of $\mathrm{PEG}_{2000}$-DSPE relative to DPPC was $0.05: 1$ ) for $60 \mathrm{~min}$ at $42^{\circ} \mathrm{C}$ in PBS buffer $(0.1 \mathrm{M}, \mathrm{pH}=8.0)$.

The bicinchoninic acid (BCA) assay (Micro BCA Protein Assay Kit, Pierce Biotechnology, USA) was used to detect the Abs content according to the manufacturer's instructions as described by Zhang et [47]. The CD90 absorbance of the diluted protein obtained from the albumin (BSA) standard solution $(0,0.025,0.05,0.1,0.2$, $0.4 \mu \mathrm{g}$ protein $/ \mu \mathrm{L}$ ) was used for standard curve preparation by using a spectrophotometer (Bio-Tek, Winooski, USA) at $568 \mathrm{~nm}$. The phospholipid concentration of liposome was determined using the Stewart method [48]. A 1-mL aliquot of CD90 liposome was dispersed into $1 \mathrm{~mL}$ chloroform solution and then was added into $2.0 \mathrm{~mL}$ ammonium ferrothiocyanate solution $(3.04 \mathrm{~g}$ ammonium thiocyanate, $2.7 \mathrm{~g}$ ferric chloride, $100 \mathrm{~mL} \mathrm{dH}_{2} \mathrm{O}$ ). After mixing for $1 \mathrm{~min}$ and centrifuging for $10 \mathrm{~min}$ at 2000 $\mathrm{rpm}$, the supernatant was analyzed by using ultravioletvisible spectrophotometry (UV-VIS spectrophotometry, UV-3600, Shimadzu, Tokyo, Japan) for the phospholipid concentration at $488 \mathrm{~nm}$. The spectrophotometrical analyzation of liposome based on the principle that phospholipids generate stable color complexes $(488 \mathrm{~nm})$ with ammonium ferrothiocyanate in the organic solution at room temperature. The absorbance of the diluted sample obtained from DPPC standard solution was used for standard curve preparation. The coupling efficiency of anti-human CD90 was calculated. The following parameters were used to calculate the final anti-CD90 density on the resulting liposome (equation below): (a) the molecular mass of CD90 (150 kD); (b) the mass of CD90; (c) the molecular mass of DPPC (734 D); (d) the mass of the phospholipids; (e) the approximate number of phospholipid (90000) [49].

$$
\text { anti-CD90 moleculars per liposome }=\frac{\text { the mass of anti-CD90/150000 }}{\text { the mass of phospholipid } / 734} \times 90000
$$

$\mathrm{CD} 90-\mathrm{Rh} / \mathrm{TMs}$ was prepared similarly.

\section{Characterization of CD90@TMs}

\section{Morphology and size analysis}

The morphology of $\mathrm{Fe}_{3} \mathrm{O}_{4}$ and CD90@TMs was assessed by TEM (Hitachi, Tokyo, Japan).

Liposome size and zeta potentials were determined using ZetaPlus analysis (Brookhaven Instruments Co., Holtsville, NY, USA). 


\section{Fourier translation infrared spectroscopy and slide agglutination assay}

FTIR was used to evaluate the successful conjunction between CD90 and Mal-PEG ${ }_{2000}$-DSPE. The spectrum of Mal-PEG ${ }_{2000}-\mathrm{DSPE}$ and CD90-PEG ${ }_{2000}-\mathrm{DSPE}$ was detected, respectively. The slide agglutination method [50] was used to evaluate the combination of anti-human CD90 with TMs and the biological activity of CD90@ TMs in vitro. First, CD90@TMs and TMs were added to two clean slides, respectively. Then the anti-mouse CD90 or saline were added in two TMs and the slides were incubated for $30 \mathrm{~min}$ at $37^{\circ} \mathrm{C}$. The agglutinate reaction was observed by optical microscopy.

\section{Characteristic analysis of thermal sensitivity}

CD90@TMs was analyzed by differential thermal analysis to evaluate the phase transition temperature. To identify the release mechanism of TMs, $\mathrm{Rh}$ release from the nanoparticles in $\mathrm{PBS}(\mathrm{pH} 7.4)$ at $37^{\circ} \mathrm{C}$ and $42^{\circ} \mathrm{C}$ was evaluated using the dynamic dialysis method. $\mathrm{Rh}$ concentration release from each sample at $0,1,2,4,6,8$, $12,24,48,96$ and $120 \mathrm{~h}$ was quantified using an F-2700 fluorescence spectrophotometer (HITACHI, Tokyo, Japan; ex/em: 570/600 nm).

\section{Stability analysis}

To assess the physical stability of the nanoparticles, the hydrodynamic size of CD90-Rh/TMs and encapsulation efficiency of the Rh in PBS and DMEM/ F12 medium were analyzed within $24 \mathrm{~h}$. The particle size and encapsulation efficiency were measured for 4 weeks with storage at $4^{\circ} \mathrm{C}$ with ambient humidity.

Hysteresis loops, specific absorption rate and increasing temperature tests

Iron content was measured using 1, 10-phenanthroline spectrophotometry as described by $\mathrm{Wu}$ [22]. The $\mathrm{Fe}_{3} \mathrm{O}_{4}$ powder and freeze-dried CD90@TMs were placed in a vibrating sample magnetometer (VSM) to determine the magnetic properties at room temperature. The CD90@TMs was placed on SPG-06A high-frequency induction heating equipment (Shenzhen, China) ( $\mathrm{f}=$ $200 \mathrm{kHz}, \mathrm{I}=20 \mathrm{~A}$ ) for $60 \mathrm{~min}$ to do the thermodynamic test. The SAR values of $\mathrm{Fe}_{3} \mathrm{O}_{4}$ and CD90@TMs were calculated as described by Xie et al.[51].

\section{Isolation of CD90+ ${ }^{+} \mathrm{CSCs}$}

Huh7 cells were mixed and incubated with $20 \mu \mathrm{L}$ CD90 MicroBeads (Miltenyi Biotec, Bergisch Gladbach, Germany) per $10^{7}$ total cells at $4^{\circ} \mathrm{C}$ for $30 \mathrm{~min}$. The cells were then washed and were applied onto a MiniMACS Column, which was placed in the magnetic field. The magnetically labeled CD90 ${ }^{+}$Huh7 cells were absorbed by the magnetic field and retained in the MiniMACS column, while CD90- Huh7 cells passed through the column and were collected. Finally, the MiniMACS column was removed from the magnetic field, the magnetically retained $\mathrm{CD}^{+} 0^{+}$cells, called $\mathrm{CD} 90^{+} \mathrm{LCSC}$ were collected by firmly pushing the plunger into the column. The sorted $\mathrm{CD}^{+}$LCSCs were cultured with DMEM/F12 medium $4 \mathrm{~h}$ and then used in CSC characteristics analysis, targeting ability assay and treatment trial. The purity of the CD90- Huh7 and CD90 ${ }^{+}$LCSCs were analyzed by Flow Cytometer (FCM, BD Biosciences, USA) after being stained with CD90-APC (Miltenyi Biotec, Bergisch Gladbach, Germany). Trypan blue staining was used as an index of cell activity.

\section{Analysis of the LCSC characteristics}

\section{Cellular proliferation and differentiation experiment}

The $\mathrm{CD}^{+}{ }^{+} \mathrm{LCSC}$ s and CD90- Huh7 cells were seeded in 96-well plates at $1 \times 10^{3} /$ well and cultured in complete RPMI 1640 with 10\% FBS for 1, 3, 5 and 7 days. Cell proliferation was assayed using a cell counting kit-8 (CCK8) assay. CD90 ${ }^{+}$LCSCs were cultured with DMEM medium supplemented with $10 \%$ fetal bovine serum. At $1,3,5$, and $7 \mathrm{~d}$, cells were collected and incubated with APC-conjugated anti-CD90 monoclonal antibody at $4{ }^{\circ} \mathrm{C}$ for $30 \mathrm{~min}$, and then analyzed by a Flow Cytometer (FCM, BD Biosciences, USA).

\section{Drug resistance}

Drug resistance of the cells to DOX was measured using a CCK8 assay. The rate of cell growth inhibition was calculated by the formula: Inhibition rate $=(O D$ value of the control group - OD value of experimental group)/ (OD value of the control group - OD value of blank Group). Drug doses to inhibit 50\% of cell growth (IC50 values) were then calculated by modified Kou-type method:

$$
\lg I C 50=X_{m}-I\left(P-\left(3-P_{m}-P_{n}\right) / 4\right)
$$

Where Xm: lg Maximum dose; I: lg (maximum dose/adjacent dose); P: sum of positive response rate; Pm: the largest positive response rate; $\mathrm{Pn}$ : the smallest positive response rate.

\section{Colony formation}

The colony-formation capacity of $\mathrm{CD}^{+} 0^{+} \mathrm{LCSCs}$ and CD90- Huh7 cells were detected by re-suspending cells in $2-\mathrm{mL}$ cell culture medium contain $0.3 \%$ low melting temperature agarose at 1500 cells per well and then seeding in six-well plates covered with $0.6 \%$ agarose. The six-well plates were then incubated for 2 weeks at $37^{\circ} \mathrm{C}, 5 \% \mathrm{CO}_{2}$ until colonies formed. Colonies $>50$ cells were counted as described previously [52].

\section{Invasion assay}

To analyze cell invasion, corning invasion chambers were coated with matrigel. The $\mathrm{CD}^{+} 0^{+} \mathrm{LCSC}$ and CD90Huh7 cells were re-suspended in $200 \mu \mathrm{L}$ of DMEM at 2.0 
$\times 10^{3} / \mathrm{mL}$ and were transferred to the lower chambers containing $500 \mu \mathrm{L}$ of DMEM with $10 \%$ FBS. After $24 \mathrm{~h}$, invasive cells were fixed in $4 \%$ paraformaldehyde for 30 min, stained with $0.1 \%$ crystal violet solution and counted under an inverted microscope.

\section{Tumor formation experiment}

NOD/SCID mice were randomized into the following three groups: control, CD90 ${ }^{+} \mathrm{LCSC}$ and CD90 Huh7 cells ( $n=6$ mice /group). Tumors were induced by subcutaneous injection of $2 \times 10^{4}$ cells. The half numbers of the mice were observed two month and the others were euthanized when the tumors were $100 \mathrm{~mm}^{3}$. The tumors were excised, fixed in $10 \%$ formalin and embedded in paraffin. HE staining was used to observed morphological and histological changes. IHC staining was used to detect the expression of CD90 in vivo.

\section{Targeting ability of CD90@TMs for $\mathrm{CD}^{+}$ LCSCs}

\section{Flow cytometry}

The CD90 ${ }^{+}$LCSCs used in the targeting experiment after $4 \mathrm{~h}$ in culture after sorted by MACS. Rh was wrapped incorporated into TMs as a fluorescent indicator of CD90@TM targeting to CD90+ LCSCs. Non-specific antibody was conjunct with TMs (CD20@TMs) to test the specificity of cellular uptake of the CD90@TMs. The expression of CD20 was detected by flow cytometry after being stained with CD20-APC (Miltenyi Biotec, Bergisch Gladbach, Germany). Flow cytometry was used to investigate the binding of $\mathrm{CD} 90-\mathrm{Rh} / \mathrm{TMs}$ to $\mathrm{CD} 90^{+}$ LCSCs. CD90 ${ }^{+}$LCSCs were incubated with CD90-Rh/ $\mathrm{TMs}, \mathrm{Rh} / \mathrm{TMs}$ and $\mathrm{Rh}(5 \mu \mathrm{g} / \mathrm{mL})$ for $1 \mathrm{~h}$ at $37^{\circ} \mathrm{C}$ in $5 \%$ $\mathrm{CO}_{2}$. CD90 ${ }^{+}$LCSCs incubated with medium or CD20-Rh/ TMs and CD90- Huh7 cells incubated with CD90-Rh/TMs for $1 \mathrm{~h}$ were used as controls.

\section{Confocal laser scanning microscopy}

Confocal laser scanning microscopy was used to assess the uptake and distribution of LCSCs to CD90Rh/TMs. CD90+LCSCs were incubated with CD90-Rh/ TMs, Rh/TMs and $5 \mu \mathrm{g} / \mathrm{mL} \mathrm{Rh}$ for $1 \mathrm{~h}$ at $37^{\circ} \mathrm{C}$ in $5 \% \mathrm{CO}_{2}$. $\mathrm{CD}^{+} 0^{+} \mathrm{LCSC}$ incubated with medium or CD20-Rh/TMs, CD90- Huh7 cells incubated with CD90-Rh/TMs for $1 \mathrm{~h}$ were used as controls.

\section{MRI assay}

The uptake of $\mathrm{Fe}_{3} \mathrm{O}_{4}$ was detected by 7.0-Telsa Micro MRI (Bruker, Germany). CD90 ${ }^{+}$LCSCs were seeded onto the 6 -well plates at $1 \times 10^{4}$ cells/well and incubated with CD90@TMs, TMs and pure $\mathrm{Fe}_{3} \mathrm{O}_{4}$ for $1 \mathrm{~h}$ at $37^{\circ} \mathrm{C}$ in $5 \% \mathrm{CO}_{2}$. CD90 $0^{+}$LCSCs incubated with medium or CD20@TMs, CD90- Huh7 cells incubated with CD90@TMs for 1 h was used as controls. Cells were resuspended by centrifugation at $1000 \mathrm{rpm}$ for $5 \mathrm{~min}$ and the supernatant was aspirated completely. Cells were then washed with PBS for three times and resuspended in $1 \%$ agarose $(0.5 \mathrm{~mL})$ in the ependoff tube. The ependoff tubes were scanned with a 7.0-Tesla MRI system. A $\mathrm{T}_{2}$ mapping sequence (TR: $2000 \mathrm{~ms}$, TE: $30 \mathrm{~ms}$, matrix $256 \times 256$, field of view [FOV] $5 \times 5 \mathrm{~cm}, 1 \mathrm{~mm}$ thick, $3.0 \mathrm{~cm}$ diameter body coil) was used to evaluate transverse relaxation time. The $\mathrm{T}_{2}$ values were calculated and recorded as the mean \pm standard deviation $(n=3)$.

\section{Prussian blue staining}

The cellular uptake of $\mathrm{Fe}_{3} \mathrm{O}_{4}$ was evaluated Prussian blue staining. After incubation with CD90@TMs, TMs and pure $\mathrm{Fe}_{3} \mathrm{O}_{4}$ for $1 \mathrm{~h}$ at $37^{\circ} \mathrm{C}$ in $5 \% \mathrm{CO}_{2}$, the cells were stained with Prussian blue solution at $37^{\circ} \mathrm{C}$ for $30 \mathrm{~min}$. CD90 ${ }^{+}$LCSCs incubated with medium or CD20@TMs, CD90- Huh7 cells incubated with CD90@TMs for $1 \mathrm{~h}$ were used as controls.

\section{Non-specific uptake assay in vitro and in vivo}

In this study, we prepared the TMs coated with PEG to reduce the uptake of MPS and get longer circulation lifetimes. The experiments in vitro and in vivo were used to confirm that the TMs coated with PEG (called liposomes@PEG) could reduce the uptake by MPS compared to the TMs not modified with PEG (called liposomes).

RAW264.7 macrophages were seeded onto the 6 -well plates at $1 \times 10^{4}$ cells/well and incubated with liposomes@PEG and liposomes for $2 \mathrm{~h}$ at $37^{\circ} \mathrm{C}$ in $5 \%$ $\mathrm{CO}_{2}$. The value of $\mathrm{T}_{2}$ was detected on a 7.0-Tesla MRI system.

The liposomes@PEG and liposomes were injected in the health mice in the $5 \mathrm{mg}$ Fe per $\mathrm{kg}$ of the mice through tail vein, respectively. MRI of the liver was performed before injection and at $0 \mathrm{~h}, 1 \mathrm{~d}$, and $3 \mathrm{~d}$ post-injection. The mapping sequence for the liver was as follows: MSME$\mathrm{T}_{2} \mathrm{WI}: \mathrm{FOV}=35 \mathrm{~mm} \times 35 \mathrm{~mm}, \mathrm{TR}=3000 \mathrm{~ms}, \mathrm{TE}=$ $20 \mathrm{~ms}$, slice thickness $=0.8 \mathrm{~mm}$, matrix $=256 \times 256$. FLASH-T ${ }_{2}^{*}$ sequence: $\mathrm{FOV}=35 \mathrm{~mm} \times 35 \mathrm{~mm}, \mathrm{TR}=$ $408 \mathrm{~ms}, \mathrm{TE}=3.5 \mathrm{~ms}$, slice thickness $=0.8 \mathrm{~mm}$, matrix $=$ $256 \times 256$. The relative signal intensity of the liver was calculated as followed: Relative signal intensity $=T_{2}$ value of the liver/ $T_{2}$ value of the muscle. $T_{2}$ relaxation times were measured by manually drawing a region of interest (ROI) within the liver areas.

\section{Treatment trial}

The sensitivity of $\mathrm{CD}^{+}{ }^{+} \mathrm{LCSCs}$, CD90- $\mathrm{Huh} 7$ cells and Huh7 cells to magnetic hyperthermia

$\mathrm{CD}^{+}$LCSCs were cultured with DMEM/F12 containing hEGF, bEGF and B27 in low-attachment plates. To determine the sensitivities of CD90 $0^{+} \mathrm{LCSCs}$, 
CD90- Huh7 and Huh7 cells to hyperthermia, the viability and apoptosis of cells exposed to AMF for $10 \mathrm{~min}, 30$ min and $1 \mathrm{~h}$ were detected. These cells were incubated with TMs for $4 \mathrm{~h}$ and then placed in an AMF to determine a defined temperature $\left(44^{\circ} \mathrm{C}\right)$. Cells incubated with TMs not exposed to AMF were used as controls. After hyperthermia, cells were washed extensively to remove TMs and then replaced with fresh medium. The viability of CD90 ${ }^{+}$LCSCs, CD90- Huh7 cells and Huh7 cells after $24 \mathrm{~h}$ was assessed by MTT assay. Apoptosis was determined by FACS Calibur flow cytometer using an Annexin V-FITC/PI apoptosis detection kit according to the manufacturer's instructions.

\section{Targeted hyperthermia using CD90@TMs for CD90+ LCSCs}

To compare the antitumor effect of CD90@TMs and TMs, the inhibition rate and apoptosis rate of $\mathrm{CD} 90^{+}$ LCSCs was assessed by MTT and annexin V- FITC/PI affinity assays. Subsequently, CD90 $0^{+} \mathrm{LCSC}$ were divided into seven groups: (1) a control group containing cells incubated with DMEM/F12, (2) an anti-CD90 MAb, (3) an anti-CD90 MAb, (4)TMs alone, unexposed to AMF, (5) CD90@TMs alone, unexposed to AMF, (6)TMs + AMF (7) CD90@TMs +AMF. All groups used $0.34 \mathrm{mg} / \mathrm{mL}$ Fe to reach a temperature of $44^{\circ} \mathrm{C}$. Cells of group 3, 4, 5, 6 were incubated with TMs or CD90@TMs for 1h and hyperthermia groups were exposed to AMF for $1 \mathrm{~h}$. Cell ultrastructure changes and the distribution of the $\mathrm{Fe}_{3} \mathrm{O}_{4}$ at the cellular level were observed by TEM. Firstly, the tumor cells were fixed in $2.5 \%$ glutaraldehyde and $1 \%$ osmium tetroxide in turn. After dehydration in graded ethanol solutions, the cells were embedded in SPI-Pon 812 (structure Probe, Inc; West Chester; USA). Ultrathin sections, stained negative by uranyl acetate and lead citrate were studied with TEM.

\section{Effect of targeted hyperthermia on the characteristics of CD90 ${ }^{+}$LCSCs}

There is no established method of determining the effects of hyperthermia on CSCs. Therefore, we investigated the characteristics of CSCs, including drug resistance, colony formation and invasion, as well as tumorigenic ability. CD90@TMs and TMs mediated hyperthermia were chosen to detect the effect of target hyperthermia and non-target hyperthermia to the characteristics of CSCs. Trypan blue staining was used as an index of cell activity prior to the experiment using the same number of cells as described previously. Tumor volume was calculated every day for 70 days with the following formula: tumor volume $=$ long diameter $\times$ short diameter ${ }^{2} / 2$.

\section{Effect of targeted hyperthermia on $\mathrm{CD}^{2} 0^{+} \mathrm{LCSCs}$ bearing mice}

When the tumor volume reached about $600 \mathrm{~mm}^{3}$, $\mathrm{CD}^{+}$LCSCs-bearing mice were randomly divided into three groups: control group; TMs group (tumors injected with TMs and exposed to AMF); CD90@TMs group (tumors injected with CD90@TMs and exposed to AMF). Each group contained six mice. After $24 \mathrm{~h}$, the hyperthermia groups were placed on an AMF (f $=200 \mathrm{kHz} ; \mathrm{I}=20 \mathrm{~A}$ ) for $60 \mathrm{~min}$ every other day. The maximal temperature of the rectal tissue did not exceed $40^{\circ} \mathrm{C}$. Seven days later, all of the mice were euthanized, and then weighed and sectioned with HE staining. The cell apoptosis rate in vivo was determined by TUNEL assay according to manufacturer's instructions (Roche, Pleasanton, CA, USA). To assess the fraction of apoptotic cells, the count of TUNEL-positive cells was calculated from five sections. The expression rate of CD90 in the tumor was also detected by IHC staining. The inhibition rate of tumor volume was calculated as (1- volume of experimental group/volume of control groups) $\times 100 \%$. The rate of inhibition of tumor mass was calculated as follows: (1-weight of experimental group/weight of control groups) $\times 100 \%$. Proteins of different groups were extracted and quantified after treatment. Protein extracts $(40 \mu \mathrm{g})$ were then separated by SDS-PAGE on $12 \%$ polyacrylamide gels and transferred to polyvinylidene fluoride membranes. Blots were blocked in 5\% nonfat milk and incubated with anti-Bcl-2 (1:1000, Zhong Shan Golden Bridge Biotechnology, China), anti-Bax (1:1000, Zhong Shan Golden Bridge Biotechnology, China), and $\beta$-actin (1:10000, Sigma, USA) antibodies at $4^{\circ} \mathrm{C}$ overnight. Secondary antibody $(1: 10000$, Thermo, USA) was incubated for $1 \mathrm{~h}$ and results visualized with SuperSignal ${ }^{\circledR}$ West Pico Chemistry Luminescent Substrate (Thermo, USA). All the experiment repeated three times.

\section{Statistical analysis}

Values represent means \pm standard deviation (SD). The data were analyzed using the SPSS 16.0 software. A $p$ value of $<0.05$ was considered to indicate significance. A $p$ value of $>0.05$ was considered to indicate no significance.

\section{Abbreviations}

HCC, hepatocellular carcinoma; BCRP1, breast cancer resistance protein 1; MGMT, O (6)-methylguanineDNA methyltransferase; MPS, mononuclear phagocytic system; CD90, cluster of differentiation 90; $\mathrm{PEG}_{2000}{ }^{-}$ DSPE, 1,2-distearoyl-sn-glycero-3-phosphoethanolamine$\mathrm{N}$-[methoxy(polyethylene glycol)-2000]; TMs, thermosensitive magnetoliposomes; LCSCs, liver cancer stem cells; AMF, alternating magnetic field; MACS, magnetic-activated cell sorting; TEM, transmission electron microscope; FTIR, fourier translation infrared spectroscopy; Rh, Lissamine rhodamine B; DSC, differential scanning calorimeter; DMEM/F12, Dulbecco's 
Modified Eagle Media: Nutrient Mixture F-12; PI, propidium iodide; FITC, fluorescein isothiocyanate isomer I; MTT, 3-(4,5)-dimethylthiahiazo (-z-y1)3,5-di- phenytetrazoliumromide; TUNEL, terminal deoxynucleotidyl transferase-mediated dUTP-biotin nick end labeling; HE, haematoxylin-eosin; FACS, flow activated cell sorting; NOD/SCID, nonobese diabetic/severe combined immunodeficien; IHC, immunohistochemical.

\section{CONFLICTS OF INTEREST} work.

The author reports no conflicts of interest in this

\section{GRANT SUPPORT}

This work was supported by the National Key Basic Research Program of China (973 Program) (Grant No. 2013CB933904, 2011CB933500), National Natural Science Foundation of China $(81271635,81301270$, 81201131), the Natural Science Foundation of Jiangsu Province (BK2012335), the Fundamental Research Funds for the Central Universities and the Regular University Graduate Student Scientific Research Innovation Projects of Jiangsu Province (KYLX_0204), and the Scientific Research Foundation of Graduate School of Southeast University and Southeast University Excellent Doctor Degree Thesis Training Fund (YBJJ1459).

\section{REFERENCES}

1. Jemal A, Bray F, Center MM, Ferlay J, Ward E, Forman D. Global cancer statistics. CA Cancer J Clin. 2011; 61: 69-90. doi: 10.3322/caac.20107.

2. Yamashita T, Kaneko S. Orchestration of hepatocellular carcinoma development by diverse liver cancer stem cells. Journal of gastroenterology. 2014; 49(7): 1105-1110. doi: 10.1007/s00535-014-0951-1.

3. Sukowati $\mathrm{CH}$, Anfuso B, Torre G, Francalanci P, Crocè LS, Tiribelli C. The expression of CD90/Thy-1 in hepatocellular carcinoma: an in vivo and in vitro study. PLoS one. 2013; 8 (10):e76830. doi: 10.1371/journal.pone.0076830.

4. Yang ZF, Ho DW, Ng MN, Lau CK, Yu WC, Ngai P, Chu PW, Lam CT, Poon RT, Fan ST. Significance of CD90+ Cancer Stem Cells in Human Liver Cancer. Cancer cell. 2008; 13(2):153-66. doi: 10.1016/j.ccr.2008.01.013.

5. Guo Z, Li LQ, Jiang JH, Ou C, Zeng LX, Xiang BD. Cancer stem cell markers correlate with early recurrence and survival in hepatocellular carcinoma. World journal of gastroenterology. 2014; 20(8):2098-106. doi: 10.3748/wjg. v20.i8.2098.

6. Ho DW, Yang ZF, Yi K, Lam CT, Ng MN, Yu WC, Lau J, Wan T, Wang X, Yan Z, Liu H, Zhang Y, Fan ST. Gene expression profiling of liver cancer stem cells by RNA- sequencing. PloS one. 2012; 7(5): e37159. doi: 10.1371/ journal.pone.0037159.

7. Dobbin ZC, Katre AA, Steg AD, Erickson BK, Shah MM, Alvarez RD, Conner MG, Schneider D, Chen D, Landen $\mathrm{CN}$. Using heterogeneity of the patient-derived xenograft model to identify the chemoresistant population in ovarian cancer. Oncotarget. 2014; 5(18): 8750. doi: 10.18632/ oncotarget.2373.

8. Kim J K, Jeon H Y, Kim H. The molecular mechanisms underlying the therapeutic resistance of cancer stem cells. Archives of pharmacal research. 2014; 1-13. doi: 10.1007/ s12272-014-0531-1.

9. Kurth I, Hein L, Mäbert K, Peitzsch C, Koi L, Cojoc M, Kunz-Schughart L, Baumann M, Dubrovska A. Cancer stem cell related markers of radioresistance in head and neck squamous cell carcinoma. Oncotarget. 2015; 6(33): 34494-34509. doi:10.18632/oncotarget.5417.

10. Kim HC, Kim E, Jeong SW, Ha TL, Park SI, Lee SG, Lee SJ, Lee SW. Magnetic nanoparticle-conjugated polymeric micelles for combined hyperthermia and chemotherapy. Nanoscale. 2015; 7:16470-16480. doi: 10.1039/c5nr04130a.

11. Lin M, Huang J, Zhang J, Wang L, Xiao W, Yu H, Li Y, Li H, Yuan C, Zhang D. The therapeutic effect of PEI$\mathrm{Mn} 0.5 \mathrm{Zn} 0.5 \mathrm{Fe} 2 \mathrm{O} 4$ nanoparticles/pEgr1-HSV-TK/GCV associated with radiation and magnet-induced heating on hepatoma. Nanoscale. 2013; 5(3): 991-1000. doi: 10.1039/ c2nr32930a.

12. Franke K, Kettering M, Lange K, Kaiser WA, Hilger I. The exposure of cancer cells to hyperthermia, iron oxide nanoparticles, and mitomycin $\mathrm{C}$ influences membrane multidrug resistance protein expression levels. International journal of nanomedicine. 2013; 8: 351. doi: 10.2147/IJN. S37465.

13. Sadhukha T, Niu L, Wiedmann TS, Panyam J. Effective elimination of cancer stem cells by magnetic hyperthermia. Molecular pharmaceutics. 2013; 10(4): 1432-1441. doi: 10.1021/mp400015b.

14. Qu Y, Li J, Ren J, Leng J, Lin C, Shi D. Enhanced synergism of thermo-chemotherapy by combining highly efficient magnetic hyperthermia with magnetothermallyfacilitated drug release. Nanoscale. 2014; 6(21): 1240812413. doi: 10.1039/c4nr03384a.

15. Gilchrist RK, Medal R, Shorey WD, Hanselman RC, Parrott JC, Taylor CB. Selective inductive heating of lymph nodes. Annals of surgery. 1957; 146 (4):596-606. (PMID: 13470751).

16. Li XH, Rong PF, Jin HK, Wang W, Tang JT. Magnetic fluid hyperthermia induced by radiofrequency capacitive field for the treatment of transplanted subcutaneous tumors in rats. Experimental and therapeutic medicine. 2012; 3 (2):279284. doi: 10.3892/etm.2011.397.

17. Kim MJ, Jang DH, Lee YI, Jung HS, Lee HJ, Choa YH. Preparation, characterization, cytotoxicity and drug release behavior of liposome-enveloped paclitaxel/Fe3O4 
nanoparticles. Journal of nanoscience and nanotechnology. 2011; 11(1): 889-893. doi: 10.1166/jnn.2011.3267.

18. Wang C, Zhang H, Chen B, Yin H, Wang W. Study of the enhanced anticancer efficacy of gambogic acid on Capan-1 pancreatic cancer cells when mediated via magnetic $\mathrm{Fe} 3 \mathrm{O} 4$ nanoparticles. International journal of nanomedicine. 2011; 6: 1929. doi: 10.2147/IJN.S24707.

19. Kneidl B, Peller M, Winter G, Lindner LH, Hossann M. Thermosensitive liposomal drug delivery systems: state of the art review. International journal of nanomedicine. 2014; 9: 4387. doi: 10.2147/IJN.S49297.

20. Ta T, Porter T M. Thermosensitive liposomes for localized delivery and triggered release of chemotherapy. Journal of controlled release. 2013; 169(1): 112-125. doi: 10.1016/j. jconrel.2013.03.036.

21. Xia S, Li P, Chen Q, Armah M, Ying X, Wu J, Lai J. In situ precipitation: a novel approach for preparation of iron-oxide magnetoliposomes. International journal of nanomedicine. 2014; 9: 2607. doi: 10.2147/IJN.S59859.

22. Yao xue xue bao. [Preparation of magnetoliposomes and its in vivo behavior on ICR mice]. [Article in Chinese]. Wu KS, Tang JT, Liu X, Zhang Q. 2004; 39(4): 288-91. (PMID: 15303661).

23. Hayashi K, Nakamura $M$, Sakamoto $W$, Yogo $T$, Miki H, Ozaki S, Abe M, Matsumoto T, Ishimura K. Superparamagnetic nanoparticle clusters for cancer theranostics combining magnetic resonance imaging and hyperthermia treatment. Theranostics. 2013; 3(6): 366. doi: $10.7150 /$ thno. 5860 .

24. Muppidi K, Pumerantz AS, Wang J, Betageri G. Development and stability studies of novel liposomal vancomycin formulations. International scholarly research network pharmaceutics. 2012; 2012:636743. doi:10.5402/2012/636743.

25. Yang ZF, Ngai P, Ho DW, Yu WC, Ng MN, Lau CK, Li ML, Tam KH, Lam CT, Poon RT, Fan ST. Identification of local and circulating cancer stem cells in human liver cancer. Hepatology. 2008; 47: 919-928. doi: 10.1002/ hep. 22082.

26. Bian AN, Gao YH, Tan KB, Liu P, Zeng GJ, Zhang X, Liu Z. Preparation of human hepatocellular carcinoma-targeted liposome microbubbles and their immunological properties. World journal of gastroenterology. 2004; 10(23): 3424-7. doi: 10.3748/wjg.v10.i23.3424.

27. Gabizon A, Catane R, Uziely B, Kaufman B, Safra T, Cohen R, Martin F, Huang A, Barenholz Y. Prolonged circulation time and enhanced accumulation in malignant exudates of doxorubicin encapsulated in polyethylene-glycol coated liposomes. Cancer research. 1994; 54(4):987-92. (PMID: 8313389).

28. Pozzi D, Colapicchioni V, Caracciolo G, Piovesana S, Capriotti AL, Palchetti S, De Grossi S, Riccioli A, Amenitsch H, Laganà A. Effect of polyethyleneglycol (PEG) chain length on the bio-nano-interactions between
PEGylated lipid nanoparticles and biological fluids: from nanostructure to uptake in cancer cells. Nanoscale. 2014; 6(5): 2782-2792. doi: 10.1039/c3nr05559k.

29. Jensen BE, Hosta-Rigau L, Spycher PR, Reimhult E, Städler B, Zelikin AN. Lipogels: surface-adherent composite hydrogels assembled from poly (vinyl alcohol) and liposomes. Nanoscale. 2013; 5(15): 6758-6766. doi: $10.1039 / \mathrm{c} 3 \mathrm{nr} 01662 \mathrm{e}$.

30. Laurent S, Dutz S, Häfeli U O, Mahmoudi M. Magnetic fluid hyperthermia: focus on superparamagnetic iron oxide nanoparticles. Advances in colloid and interface science. 2011; 166(1): 8-23.doi:10.1016/j.cis.2011.04.003.

31. Wang G, Xu D, Chai Q, Tan X, Zhang Y, Gu N, Tang J. Magnetic fluid hyperthermia inhibits the growth of breast carcinoma and downregulates vascular endothelial growth factor expression. Oncology letters. 2014; 7(5):1370-1374. doi: 10.3892/ol.2014.1893.

32. Wang ZY, Song J, Zhang DS. Nanosized As2O3/Fe2O3 complexes combined with magnetic fluid hyperthermia selectively target liver cancer cells. World journal of gastroenterology. 2009; 15(24):2995-3002. doi: 10.3748/ wjg.15.2995.

33. Burke AR, Singh RN, Carroll DL, Wood JC, D'Agostino RB Jr, Ajayan PM, Torti FM, Torti SV. The resistance of breast cancer stems cells to conventional hyperthermia and their sensitivity to nanoparticle-mediated photothermal therapy. Biomaterials. 2012; 33(10):2961-70. doi: 10.1016/j.biomaterials.2011.12.052.

34. Creixell M, Bohórquez AC, Torres-Lugo M, Rinaldi C. EGFR-targeted magnetic nanoparticle heaters kill cancer cells without a perceptible temperature rise. American chemical society nano. 2011; 5(9): 7124-7129. doi: 10.1021/nn201822b.

35. Wu CC, Yang YC, Hsu YT, Wu TC, Hung CF, Huang JT, Chang CL. Nanoparticle-induced intraperitoneal hyperthermia and targeted photoablation in treating ovarian cance. Oncotarget. 2015; 6(29): 26861-26875. doi: 10.18632/oncotarget.4766.

36. Wang B, Armstrong JS, Lee JH, Bhalala U, Kulikowicz E, Zhang H, Reyes M, Moy N, Spicer D. Rewarming from therapeutic hypothermia induces cortical neuron apoptosis in a swine model of neonatal hypoxic-ischemic encephalopathy. Journal of cerebral blood flow \& metabolism. 2015. doi: 10.1038/jcbfm.2014.245.

37. Iacovelli S, Ricciardi MR, Allegretti M, Mirabilii S, Licchetta R, Bergamo P, Rinaldo C, Zeuner A, Foà R, Milella M, McCubrey JA, Martelli AM, Tafuri A. Cotargeting of Bcl-2 and mTOR pathway triggers synergistic apoptosis in $\mathrm{BH} 3$ mimetics resistant acute lymphoblastic leukemia. Oncotarget. 2015; 6(31): 32089-32103. doi: 10.18632/oncotarget.5156.

38. Jarskog LF, Selinger ES, Lieberman JA, Gilmore JH. Apoptotic proteins in the temporal cortex in schizophrenia: high Bax/Bcl-2 ratio without caspase-3 activation. Am J Psychiatry. 2004; 161(1): 109-15. doi: 10.1176/appi. 
ajp.161.1.109.

39. Liu YX. Temperature control of spermatogenesis and prospect of male contraception. Frontiers in biosciencelandmark. 2010; 2(2010):730-55. doi: 10.2741/s97.

40. Durairajanayagam D, Agarwal A, Ong C. Causes, effects and molecular mechanisms of testicular heat stress. Reproductive biomedicine online. 2015; 30(1): 14-27. doi: 10.1016/j.rbmo.2014.09.018.

41. Zhang L, Li H, Ge C, Li M, Zhao FY, Hou HL, Zhu MX, Tian H, Zhang LX, Chen TY, Jiang GP, Xie HY, Cui Y, et al. Inhibitory effects of transcription factor Ikaros on the expression of liver cancer stem cell marker CD133 in hepatocellular carcinoma. Oncotarget. 2014; 5(21): 10621. doi: 10.18632/oncotarget.2524.

42. Song CW, Lin JC, Lyons JC. Antitumor effect of interleukin 1 alpha in combination with hyperthermia. Cancer research. 1993; 53(2):324-8. (PMID: 8417825).

43. Atkinson RL, Zhang M, Diagaradjane P, Peddibhotla S, Contreras A, Hilsenbeck SG, Woodward WA, Krishnan S, Chang JC, Rosen JM. Thermal enhancement with optically activated gold nanoshells sensitizes breast cancer stem cells to radiation therapy. Science translational medicine. 2010; 2(55): 55ra79-55ra79. doi: 10.1126/scitranslmed.3001447.

44. Li Y, Liu J, Zhong Y, Zhang J, Wang Z, Wang L, An Y, Lin M, Gao Z, Zhang D. Biocompatibility of Fe3O4@Au composite magnetic nanoparticles in vitro and in vivo. International journal of nanomedicine. 2011; 6: 2805-2819. doi: 10.2147/IJN.S24596.

45. Wang L, Zhang J, An Y, Wang Z, Liu J, Li Y, Zhang D. A study on the thermochemotherapy effect of nanosized As2O3/MZF thermosensitive magnetoliposomes on experimental hepatoma in vitro and in vivo. Nanotechnology. 2011; 22(31):315102. doi: 10.1088/0957$4484 / 22 / 31 / 315102$.
46. Zhang W, Wang G, See E, Shaw JP, Baguley BC, Liu J, Amirapu S, Wu Z. Post-insertion of poloxamer 188 strengthened liposomal membrane and reduced drug irritancy and in vivo precipitation, superior to PEGylation. Journal of Controlled Release. 2015; 203: 161-169. doi: 10.1016/j.jconrel.2015.02.026.

47. Boot EP, Koning GA, Storm G, Wagenaar-Hilbers JP, van Eden W, Everse LA, Wauben MH. CD134 as target for specific drug delivery to auto-aggressive CD4+ T cells in adjuvant arthritis. Arthritis research \& therapy. 2005; 7(3):R604-15. doi: 10.1186/ar1722.

48. Stewart J C M. Colorimetric determination of phospholipids with ammonium ferrothiocyanate. Analytical biochemistry. 1980; 104(1): 10-14. doi: 10.1016/0003-2697(80)90269-9.

49. Loomis K, Smith B, Feng Y, Garg H, Yavlovich A, Campbell-Massa R, Dimitrov DS, Blumenthal R, Xiao X, Puri A. Specific targeting to B cells by lipid-based nanoparticles conjugated with a novel CD22-ScFv. Experimental and molecular pathology. 2010; 88(2): 238249. doi: 10.1016/j.yexmp.2010.01.006.

50. Bian AN, Gao YH, Tan KB, Liu P, Zeng GJ, Zhang X, Liu $Z$. Preparation of human hepatocellular carcinoma-targeted liposome microbubbles and their immunological properties. World journal of gastroenterology. 2004; 10(23): 3424-7. doi: 10.3748/wjg.v10.i23.3424.

51. Xie J, Yan C, Zhang Y, Gu N. Shape Evolution of "Multibranched" Mn-Zn Ferrite Nanostructures with High Performance: A Transformation of Nanocrystals into Nanoclusters. Chemistry of materials. 2013; doi: 10.1021/ cm402036d.

52. Marjanović S, Mijusković Z, Stamatović D, Madjaru L, Ralić T, Trimcev J, Stojanović J, Radović V. Multiple myeloma invasion of the central nervous system. Vojnosanitetski pregled. 2012; 69(2): 209-213. doi: 10.2298/VSP1202209M. 